NBSIR 83-2683

\title{
Description of a CMOS Test Chip, NBS-39
}

U.S. DEPARTMENT OF COMMERCE

National Bureau of Standards

National Engineering Laboratory

Center for Electronics and Electrical Engineering

Semiconductor Devices and Circuits Division

Washington, DC 20234

Aprił 1983
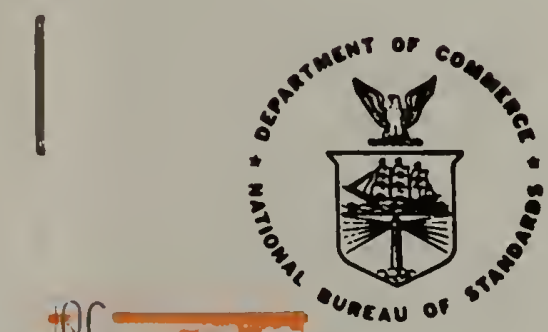

NBSIR 83-2683

DESCRIPTION OF A CMOS TEST CHIP. NBS-39

T. J. Russell

U.S. DEPARTMENT OF COMMERCE

National Bureau of Standards

National Engineering Laboratory

Center for Electronics and Electrical Engineering

Semiconductor Devices and Circuits Division

Washington, DC 20234 

Table of Contents

Abstract . . . . . . . . . . . . . . . . . . . 1

Description . . . . . . . . . . . . . . . . . . 2

Acknowledgments . . . . . . . . . . . . . . . 6 6

References ... . . . . . . . . . . . . . . . 6

List of Figures and Table

1. The CMOS Test Chip NBS-39 . . . . . . . . . . . . . . . . . . . 8

2. The key to the shading in figures for the JI-CMOS process . . . . . . . 9

3. Subsection N-1 . . . . . . . . . . . . . . . . . . . 10

1. Subsection N-2 . . . . . . . . . . . . . . . . . . . 11

5. Subsection P-1 . . . . . . . . . . . . . . . . . . . . . 12

6. Subsection P-2 . . . . . . . . . . . . . . . . . . . . . . 13

7. An n-channel MOSFET . . . . . . . . . . . . . . . . . . . 14

8. A p-channel MOSFET . . . . . . . . . . . . . . . . . . . 15

9. An $n^{+}$doped polysilicon cross-bridge sheet resistor test structure . . . . 16

10. A $p^{+}$doped polysilicon cross-bridge sheet resistor test structure . . . . 17

11. The subsection PP-1 . . . . . . . . . . . . . . . . . . . . 18

12. The subsection PP-2 . . . . . . . . . . . . . . . . . . . 19

13. A contact resistor test structure . . . . . . . . . . . . . . . 20

14. An MOS capacitor test structure . . . . . . . . . . . . . 21 
15. An electrical alignment resistor test structure . . . . . . . . . . . 22

18. A metal gate field oxide $n$-channel MOSFE'T . . . . . . . . . . . 23

17. A metal gate intermediate oxide $n$-channcl MOSFET . . . . . . . . 24

18. An $n^{+}$secondary ion mass spectroscopy profiling target . . . . . . . 25

Table 1. Test Structure List for CMOS Test Chip NBS-39 . . . . . . . . . 28 
Description of a CMOS Test Chip, NBS-39

\author{
T. J. Russell \\ Semiconductor Devices and Circuits Division \\ National Bureau of Standards \\ Washington, DC 20234
}

\begin{abstract}
Test chip NBS-39 was designed to analyze the scaling properties of short-channel metal-oxide-semiconductor field effect transistors(MOSFETs). This report is a guide for identifying and locating each test structure included on the test chip. There is a table with each test structure identified by name, number, parameter measured, and a reference of how to perform the measurement when appropriate. The test chip can be fabricated by a junction-isolated(JI) silicon complementary metal-oxide semiconductor(CMOS) p-well process and by a local oxidation of silicon(LOCOS) CMOS $p$-well process. The modifications required to go from a JI-CMOS fabrication process to a LOCOS-CMOS are discussed.
\end{abstract}

Key words: CMOS; MOSFETs; p-well junction-isolated (JI) CMOS process; p-well local oxidation of silicon (LOCOS) CMOS process; scaling; short-channel; test chip; test structure. 


\section{Description}

CMOS test chip NBS-39 was designed to analyze the scaling properties of shortchannel MOSFETs. The test chip is shown in figure 1. The chip is divided into six subsections. Subsections labeled N-1, N-2, P-1, and P-2 contain arrrays of $n$ - and $p$-channel MOSFETS with different gate lengths and the same gate width. In addition, there are $n^{+}$and $p^{+}$doped polysilicon cross-bridge sheet resistor test structures with design bridge width equal to the adjacent transistor design gate length. Each structure contains probe pads in $2 \times \mathrm{N}$ array for electrical testing utilizing a manual probe station or a computer-controlled wafer prober. Selected transistors in each subsection are connected to the bonding pads around the periphery of the test chip. The chips can be packaged and the transistors bonded out for experiments which require that the transistor be under bias during test. Subsections labeled PP-1 and PP-2 contain process parameter test structures which can be used to characterize the process used to fabricate the transistors.

The design rules used for the layout of the test structures on the test chip had a

minimum feature size of $5 \mu \mathrm{m}$. In selected cases, the gate length of some transistors and the bridge width of some of the cross-bridge sheet resistor test structures were smaller than the minimum feature.

The test chip can be fabricated by a junction-isolated(JI) p-well CMOS fabrication process or by a p-well LOCOS-CMOS fabrication process. Both processes use a $p$-well for the $n$-channel transistors, self-aligned polysilicon gates, and single-level metallization. The changes, although minor, apply to a particular JI process and 
a particular LOCOS process and may not be applicable to other JI and LOCOS processes. The level-by-level design file for a JI-CMOS process is as follows:

1. $p$-well

2. $p^{+}$guard band

3. Thick oxide opening

4. Polysilicon

5. $n^{+}$source-drain

6. $p^{+}$source-drain

7. Contact opening

8. Metal

9. Protective oxide overcoat.

The design file used for the JI process was converted into a CalTech Intermediate Form(CIF) file[1] with design rules compatible with a p-well LOCOS silicon foundry[2].

A list of the levels including changes to the corresponding JI levels listed in parentheses follows:

1. Active area(level 5 and $6, n^{+}$and $p^{+}$source and drain implants)

2. $p$-well(level 1 and $2, p$-well and $p^{+}$guard band)

3. No equivalent level 


\section{Polysilicon}

5. $p^{+}$source-drain(level $6, p^{+}$source-drain)

6. The logical NOT of level 5 is used to define the $n^{+}$source-drain regions

7. Contact opening(no change)

8. Metal(no change)

9. Passivation(no change).

Table 1 is a list of each test structure included on the test chip NBS-39. Each structure is identified by name, number, critical dimension, and the parameter measured. Test structures are identified by $\mathrm{N}$ followed by a number and $\mathrm{P}$ followed by a number according to their use to measure $n$-type or $p$-type parametrics, respectively. References to appropriate measurement techniques are provided for selected struclures. For example, there is reference to the measurement of the misalignment between two conducting layers using an electrical alignment test structure[3], but there is no reference to the measurement of transistor characteristics.

Figure 2 is the key to the shading for the JI-CMOS process structures shown in the figures. Subsections $\mathrm{N}-1, \mathrm{~N}-2, \mathrm{P}-1$, and P-2 are shown in figures 3, 4, 5, and 6, respectively. An $n$ - and a $p$-channel transistor are shown in figures 7 and 8 , respectively. The transistors are representative of the other transistors in the $\mathrm{N}$ and $\mathrm{P}$ - subsections. The differences are only in the polysilicon gate length noted in Table 1. From left to right in subsection $\mathrm{N}-1$, transistors with gate lengths of 8,4 , 
and $1.25 \mu \mathrm{m}$ and in subsection $\mathrm{N}-2$ transistors with gate lengths of $3.5,3.0$, and 1.0 $\mu \mathrm{m}$ are connected to the bonding pads around the periphery of the test chip. From right to left in the P-1 and P-2 subsections, transistors with gate lengths of 8,4 , and $1.25 \mu \mathrm{m}$ and 3.5, 3.0, and $1.0 \mu \mathrm{m}$, respectively, are connected to the bonding pads around the periphery.

In subsections $\mathrm{N}-1$ and $\mathrm{N}-2$, the polysilicon cross-bridge sheet resistor test structures are doped with the $n^{+}$source-drain implant $n^{+}$doped and in P-1 and P-2 subsections they are doped with the $p^{+}$source drain implant. Representative $n^{+}$ and $p^{+}$doped polysilicon cross-bridge sheet resistor test structures are shown in figures 9 and 10. The width of the bridge of the sheet resislor is designed to be equal to the gate length of the adjacent MOSFET. The gate dimensions are found in Table 1.

Process parameter test structures which address properties of $n$-channel devices are labeled N59-N69 and those that address properties of $p$-channel devices are labeled P57-P68. These structures are grouped into subsections PP-1 and PP-2 and are shown in figures 11 and 12. In subsections PP-1 and PP-2, there are test structures to be used to measure contact resistance[4] (fig. 13); MOS capacitors (fig. 14) to be used to measure gate oxide properties and interface trapped charge(ITC); cross-bridge sheet resistors[5] (fig. 9) to be used to measure the sheet resistance of the various conducting layers used to fabricate devices and circuits; and electrical alignment resistors $[8]$ to be used to measure the misalignment between a contact window and a conducting layer (fig. 15). There are metal gate $n$ - and $p$-channel transistors to be used for characterizing the field oxide (fig. 16) and the intermediate field oxide (fig. 17). The large area structures N61 (fig. 18), and P61 are for secondary 
ion mass spectroscopy(SIMS) profiling of the sources and drains in the $p$ - and $n-$ channel transistors. A NAND, a NOR, and four experimental structures, dual-gated diodes and split cross-bridge sheet resistors are included, but are not illustrated or discussed.

\section{Acknowledgments}

The author would like to acknowledge all of the members of the staff of the Semiconductor Devices and Circuits Division for their contributions to the design of the CMOS Test Chip NBS-39. In particular, the author would like to thank C. L. Wilson, K. F. Galloway and L. W. Linholm for their reading of the manuscript and their useful suggestions and E. J. Walters for preparing the manuscript.

\section{References}

1. Mead, C. A., and Conway, L. A., Introduction to VLSI Design, (Addison Wesley, Reading 1980).

2. Griswold, T. W., Portable Design Rules for Bulk CMOS, VLSI Design III, No. 5, 62-67(1982).

3. Russell, T. J., Leedy, T. F., and Mattis, R. L., A Comparison of Electrical and Visual Alignment Test Structures for Evaluating Photomask Alignment in Integrated Circuit Manufacturing, Technical Digest, International Electron Devices Meeting, Washington, D.C., December 5-7, 1977, pp.7A-7F and Russell, T. J. and 
Maxwell, D. A.,Semiconductor Measurement Technology: A Production-Compatible Microelectronic Test Pattern for Evaluating Photomask Misalignment, NBS Spec. Publ.400-51(April 1979).

4. Proctor, S. J., and Linholm, L. W., A Direct Measurement of Interfacial Contact Resistance, IEEE Electron Device Lett. EDL-3, 294-296(1982).

5. Buehler, M. G., Grant, S. D., and Thurber, W. R., Bridge and van der Pauw Sheet Resistors for Characterizing the Line Width of Conducting Layers, J. Electrochemical Soc. 125, 650-654(1978).

6. Takacs, D., Muller, W., and Schwabe, U., Electrical Measurement of Feature Size in MOS $\mathrm{Si}^{2}$-Gate VLSI Technology, IEEE Trans. Electron Devices ED-27, 13681373(1980).

7. Brugler, J. S., and Jespers, P. G. A., Charge Pumping in MOS Devices, IEEE Thans. Electron Devices ED-16, 297-302(1969).

8. Russell, T. J., Wilson, C. L., and Gaitan, M., Determination of the Spatial Variation of Interface Trapped Charge Using Short-Channel MOSFETs (submitted to IEEE Trans. Electron Devices for publication). 


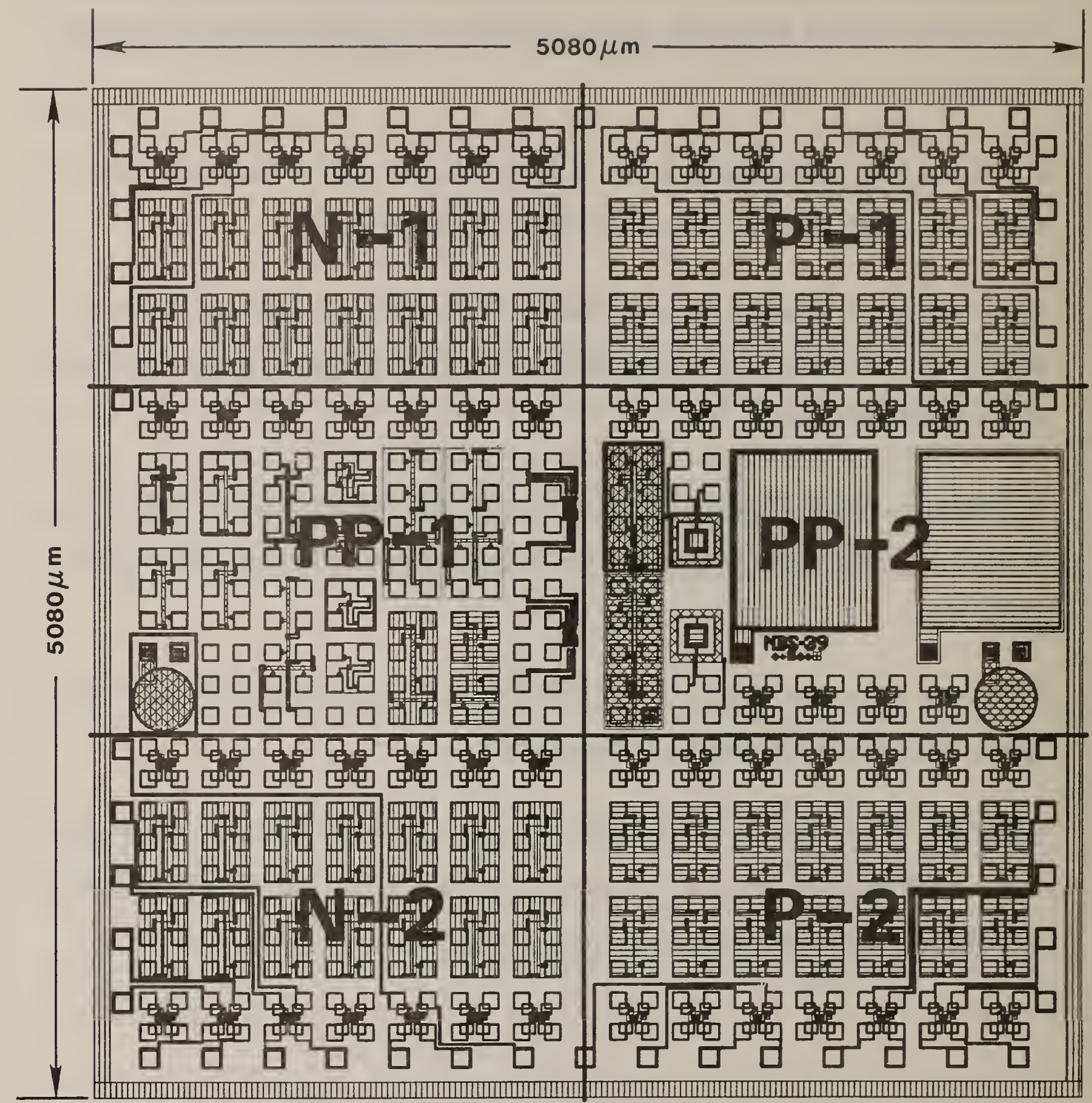

Figure 1. The CMOS Test Chip NBS-39 is shown with its six subsections labeled N-1, N-2, P-1, P-2, PP-1, and PP-2. 

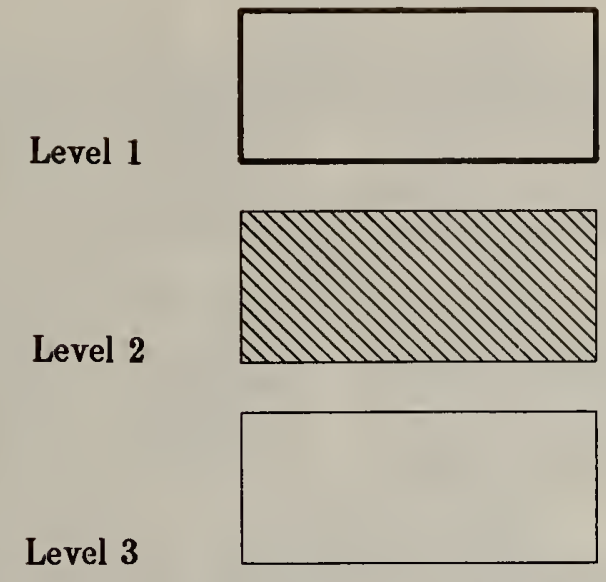

Level 4
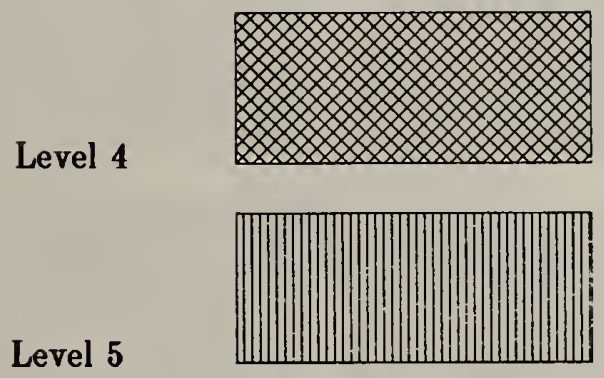

Level 6

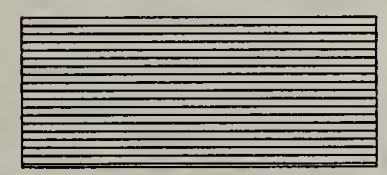

Level 7
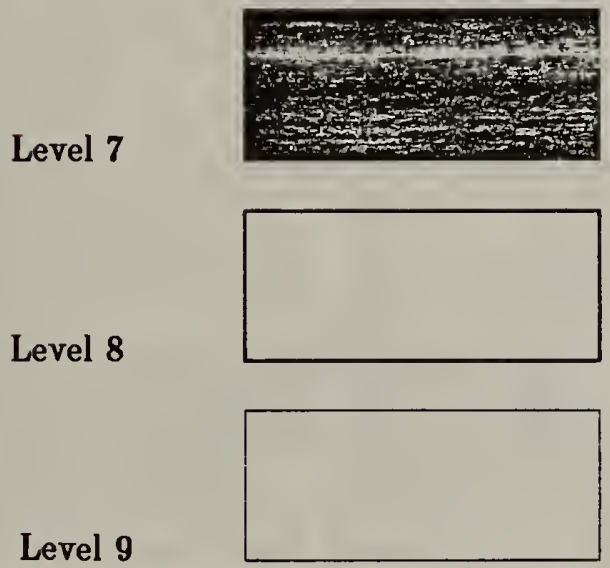

Figure 2. The key to the shading in figures for the JI-CMOS process. 


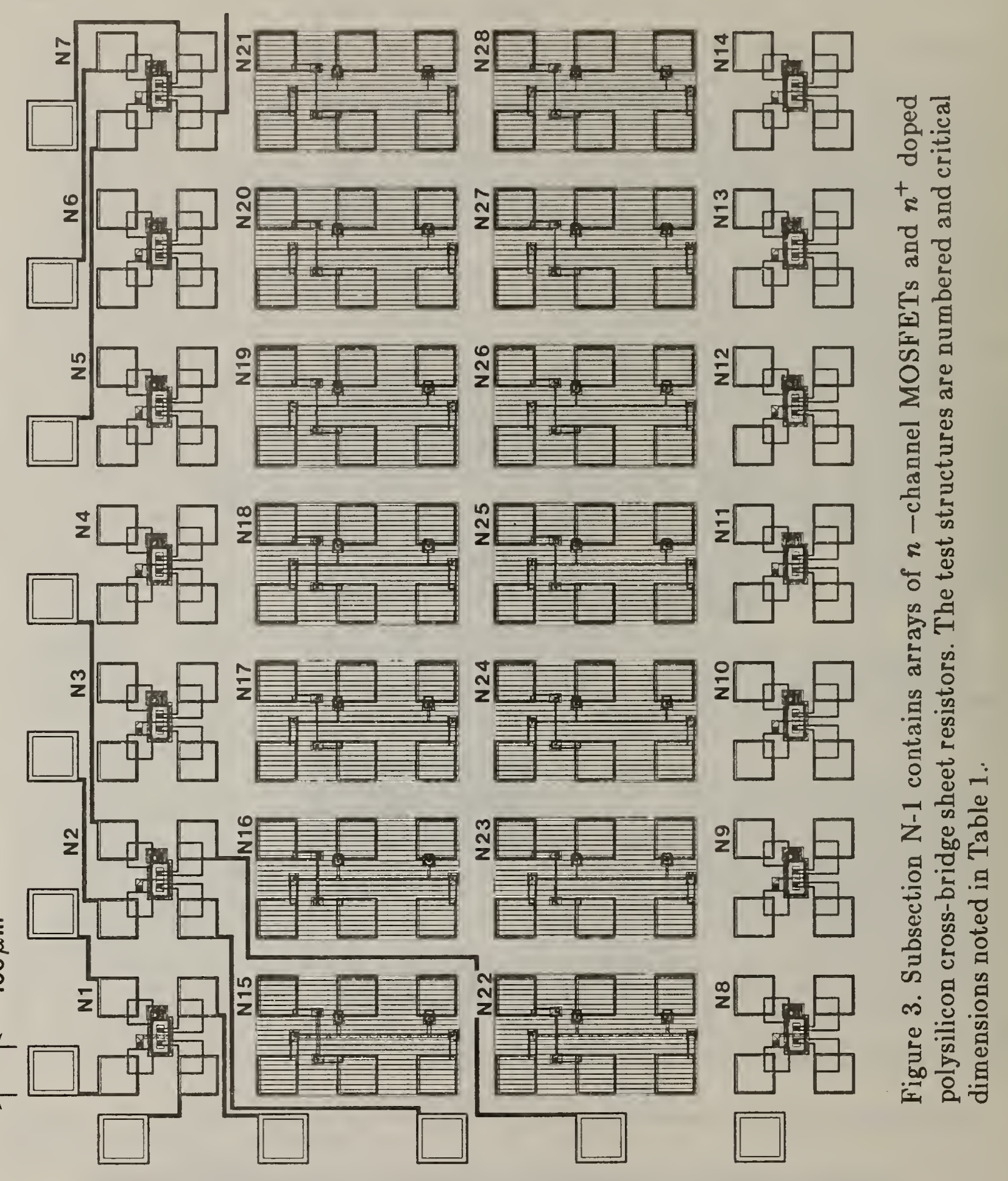




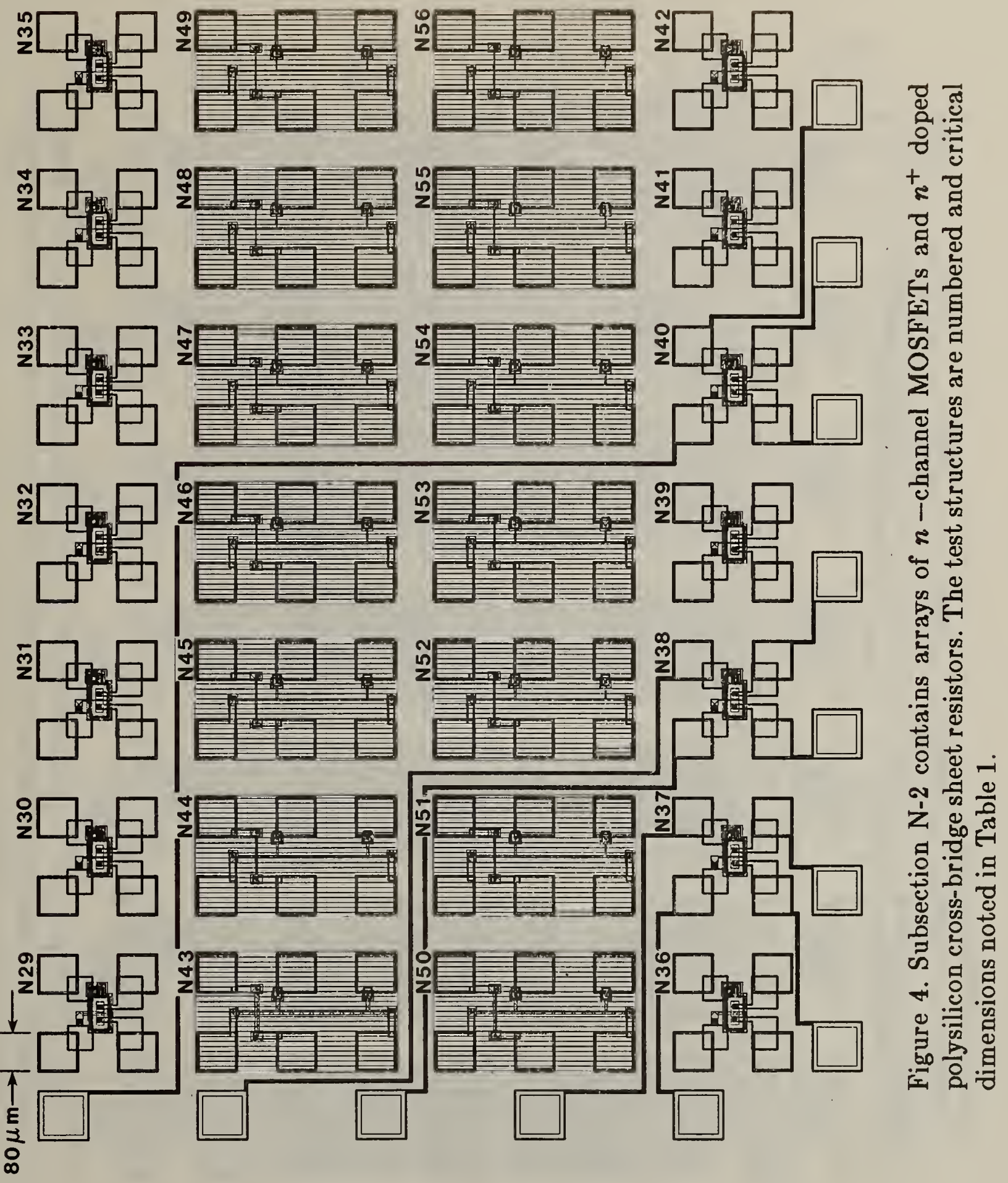




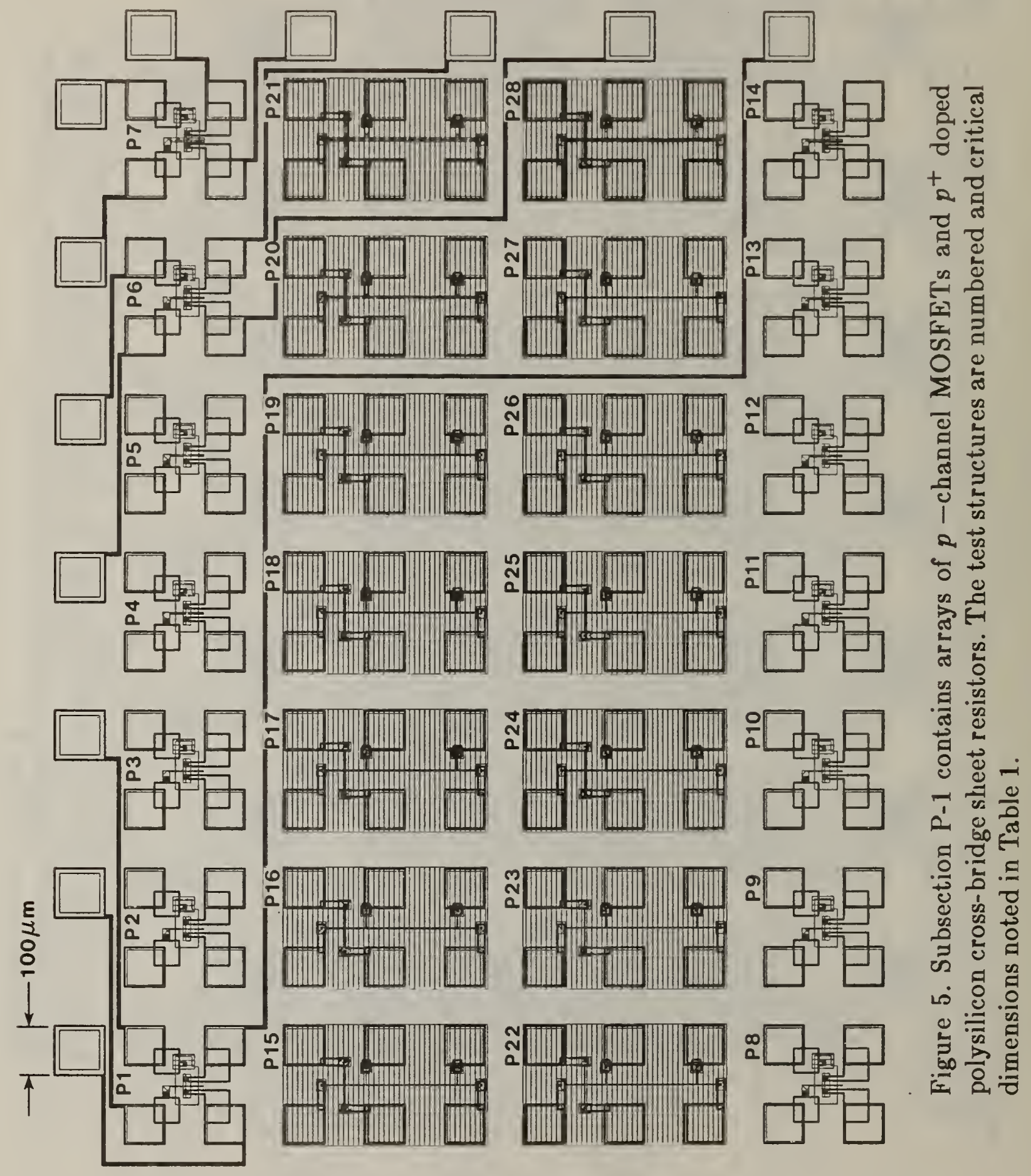


$\square$

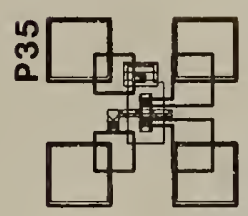

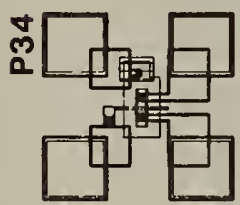

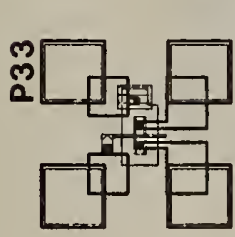

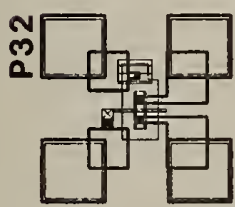

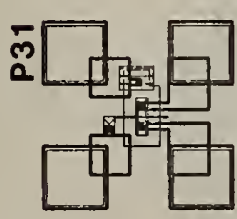

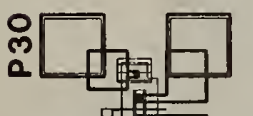

प⿺⿻一𠃋十

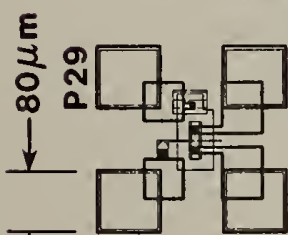

$T$
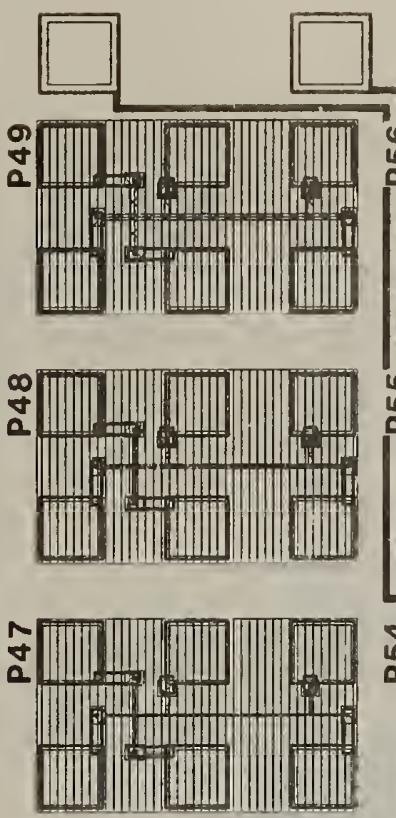

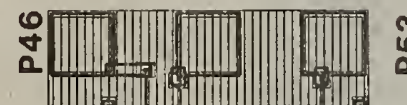
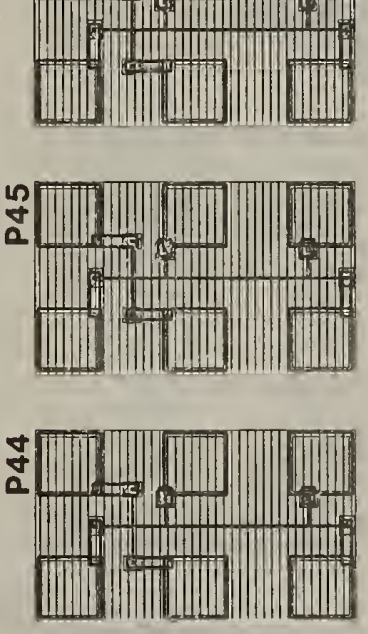

:

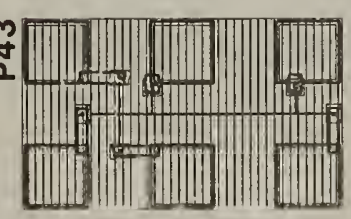

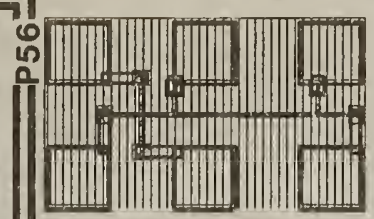
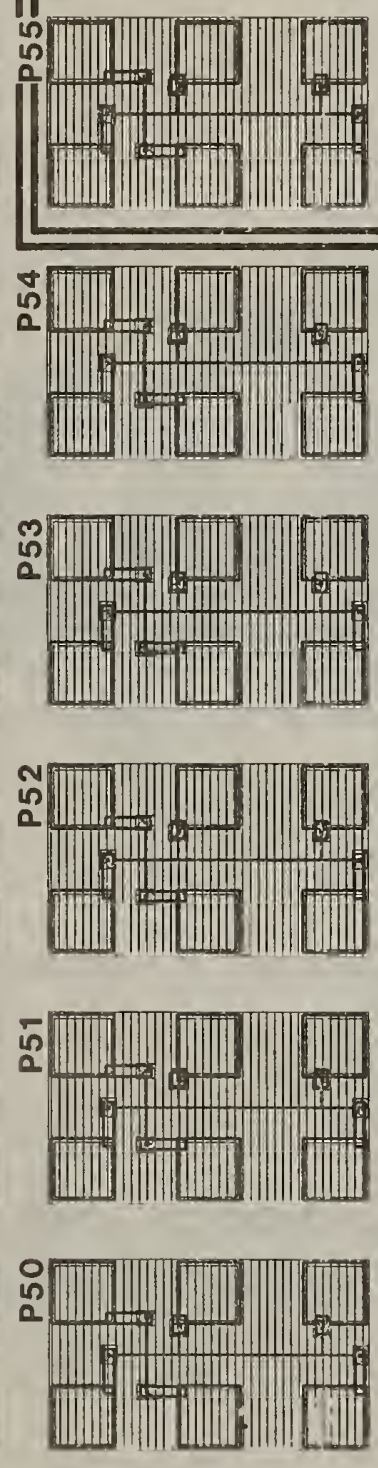
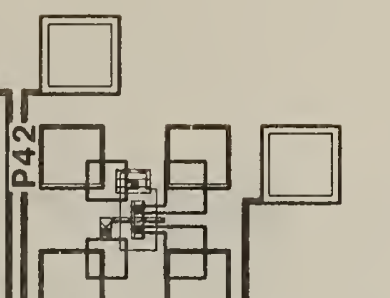

율.

+ ,

व

ส

क :

의

독

0

$\sum \pi$

o

疍

赵?

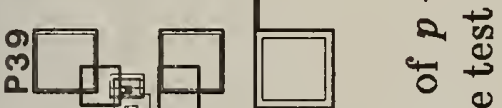

4
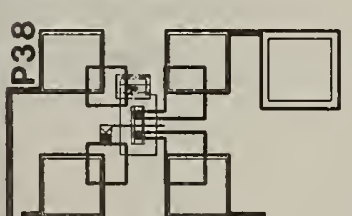

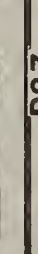
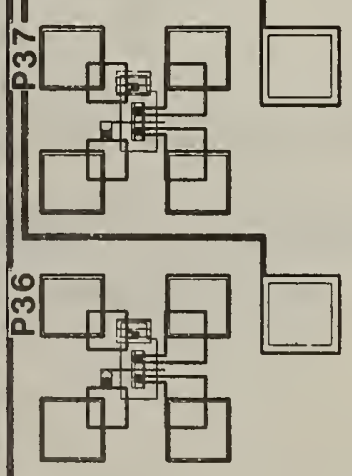

o

乎

कั้

里

절

运出

원

¿.

뭉으

을

岂 d

올

园

$\infty \stackrel{0}{\circ}$

핵

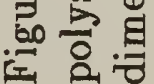




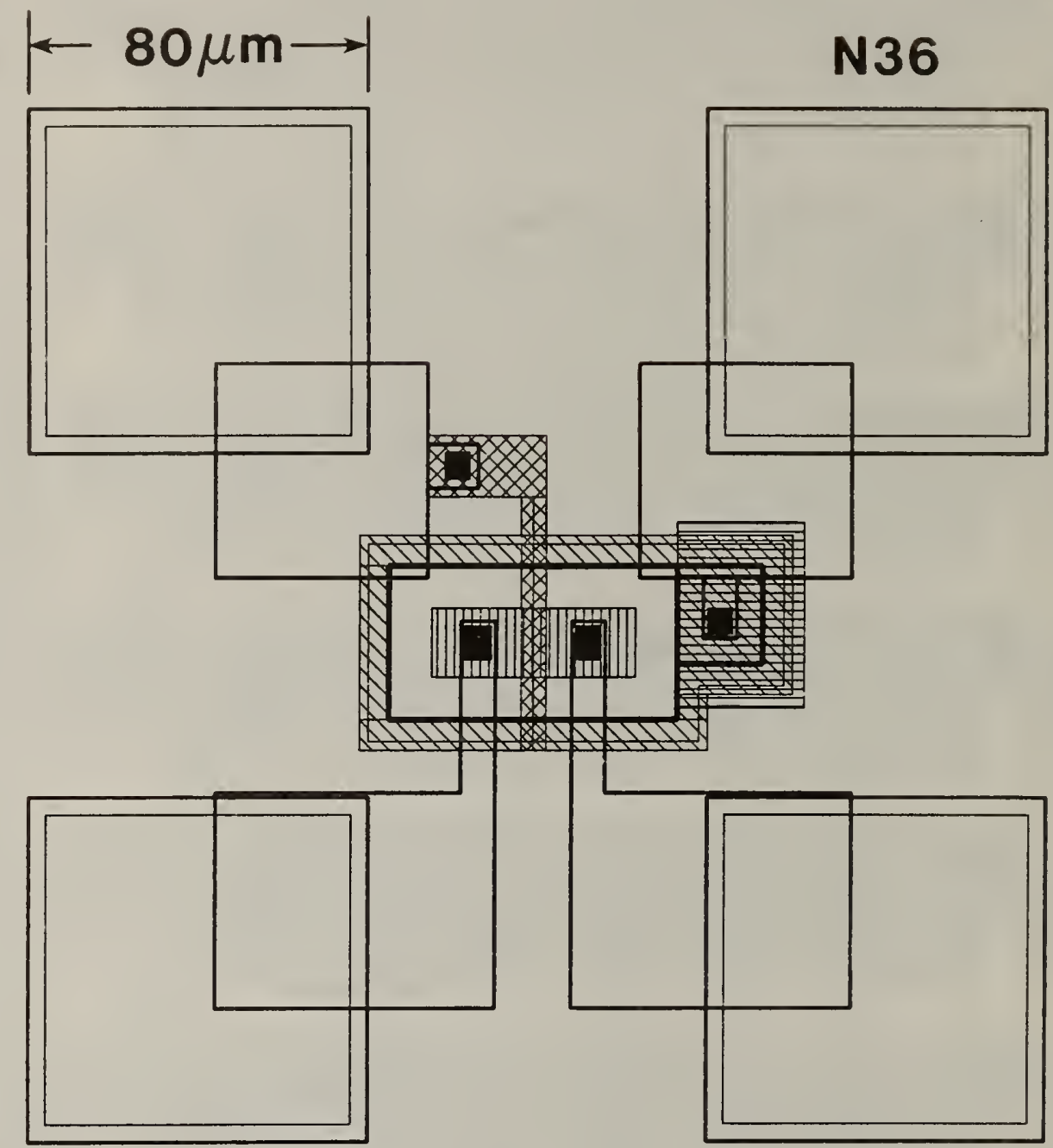

Figure 7. An $n$-channel MOSFET, N36, from subsection N-1. 


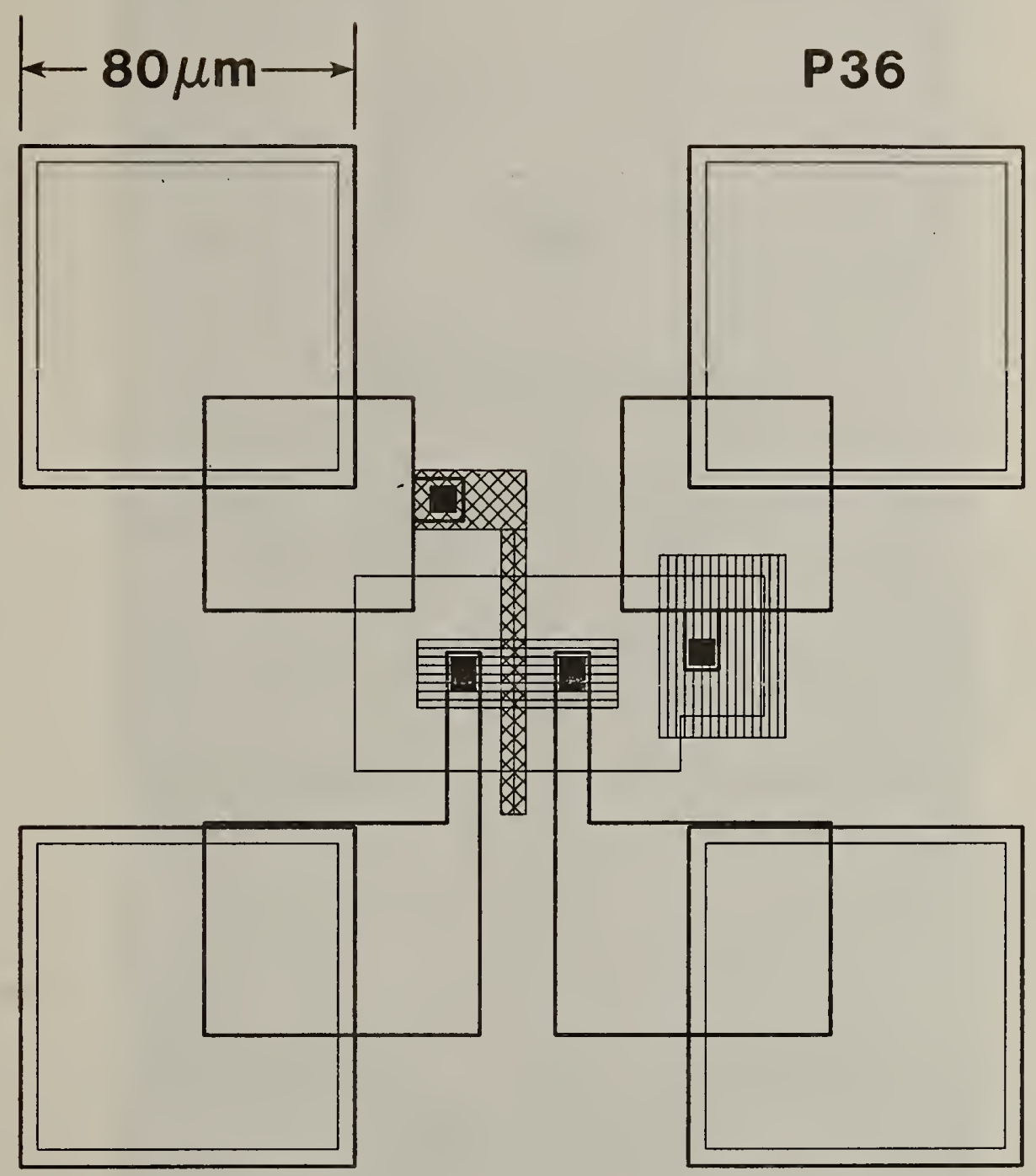

Figure 8. A p-channel MOSFET, P36, from subsection P-1. 


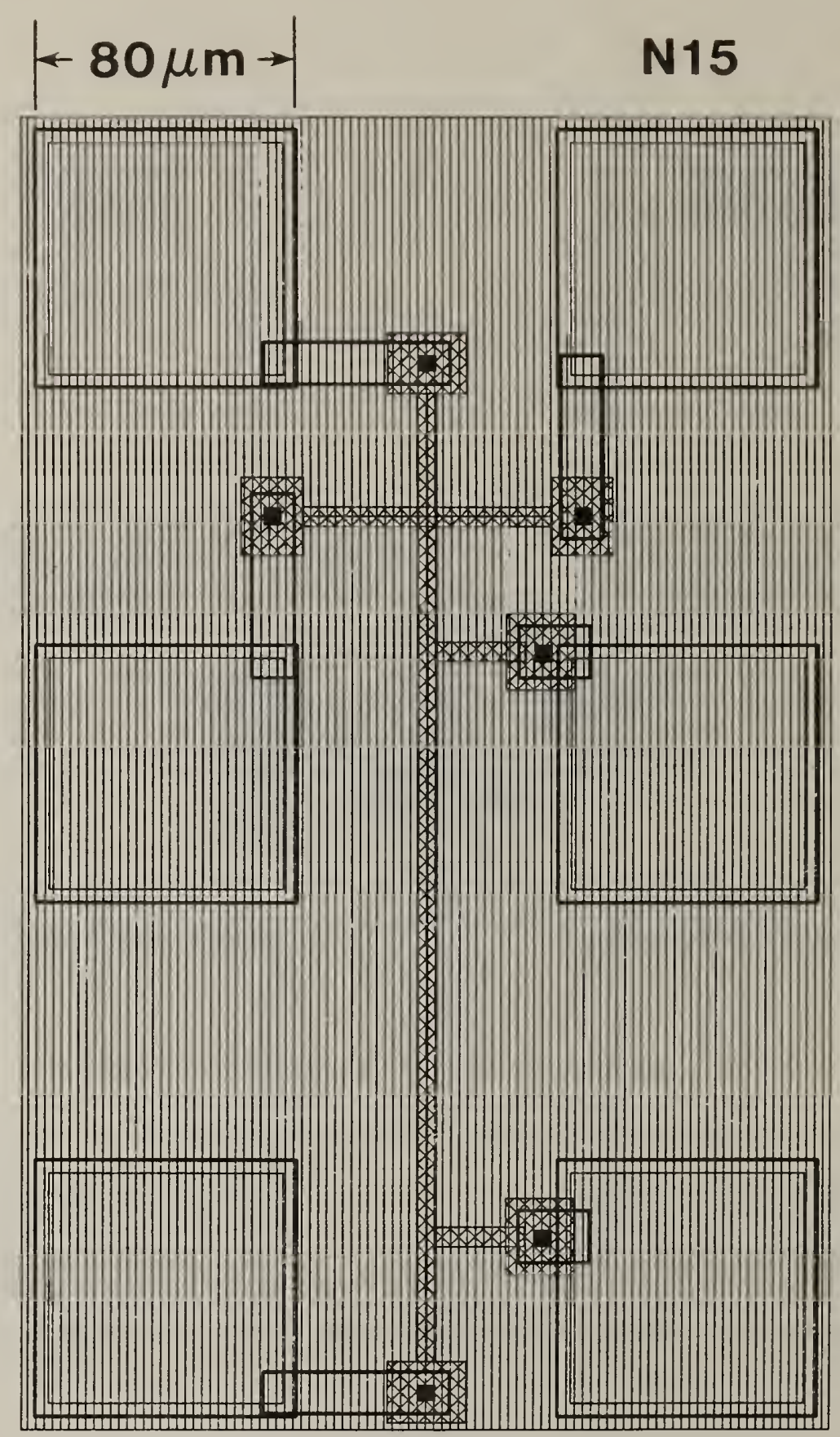

Figure 9. An $n^{+}$doped polysilicon cross-bridge sheet resistor test structure, N15, from subsection $\mathrm{N}-1$. 


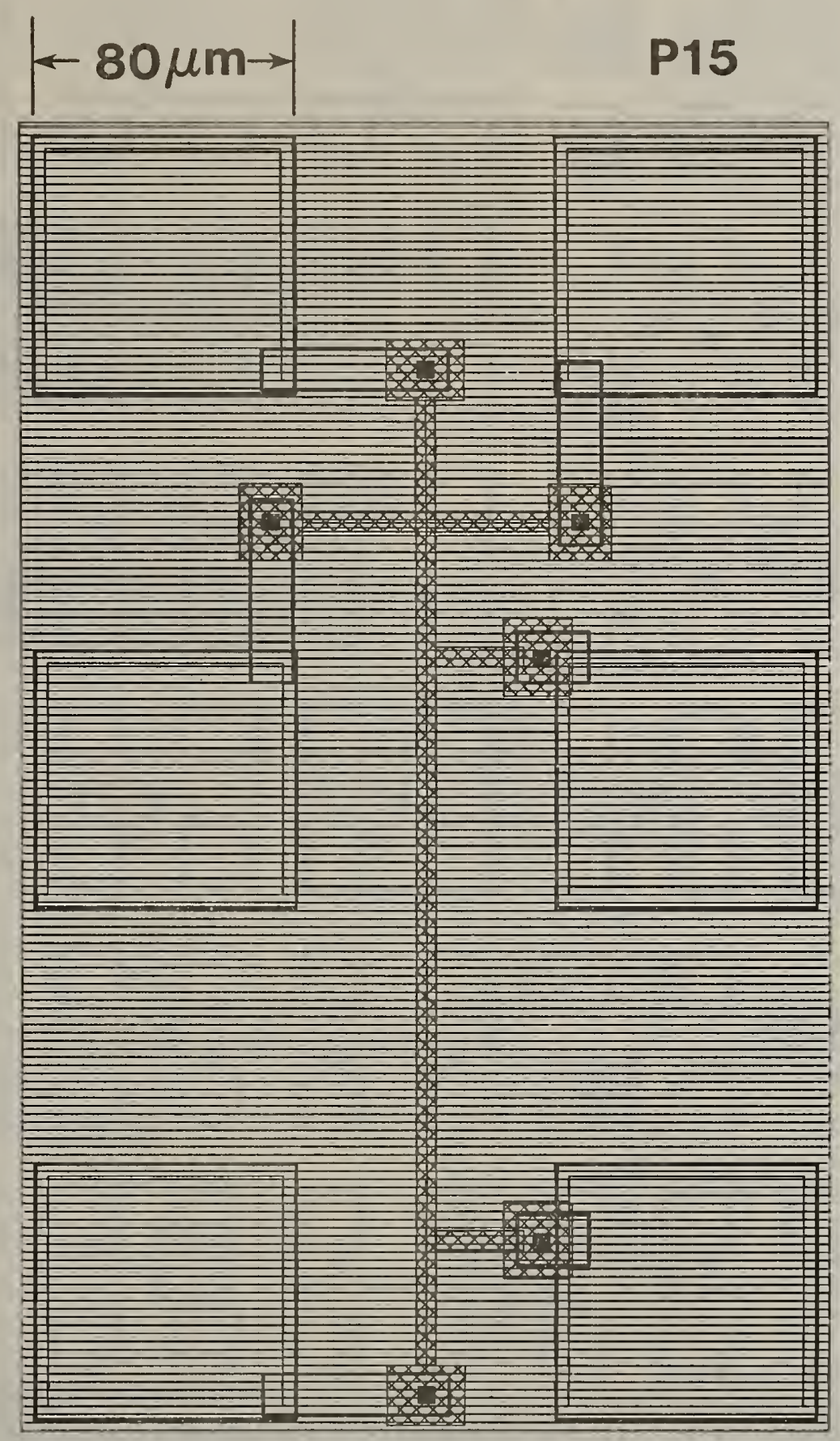

Figure 10. A $p^{+}$doped polysilicon cross-bridge sheet resistor test structure, P15, from subsection P-1. 

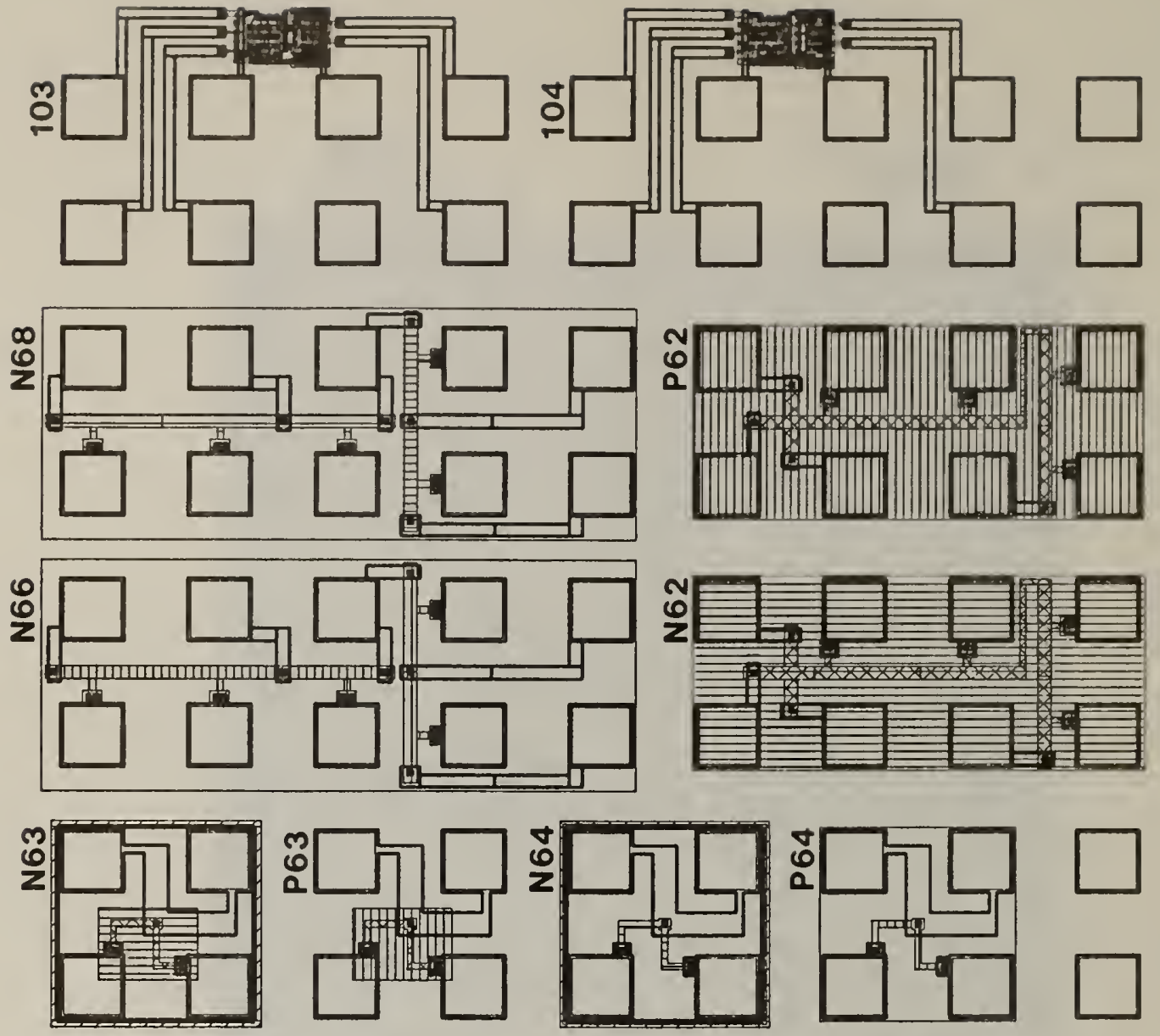

峞

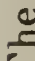
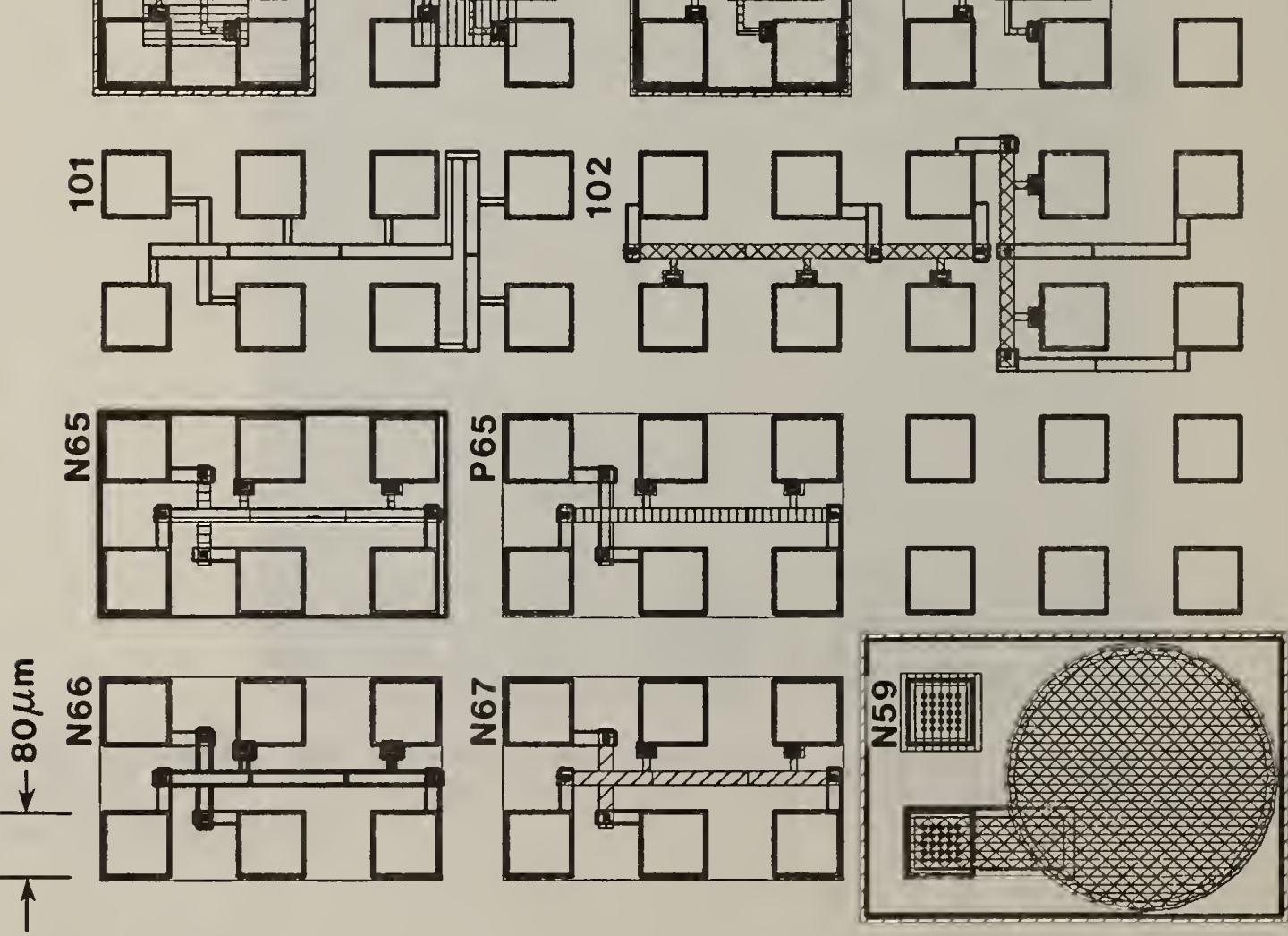


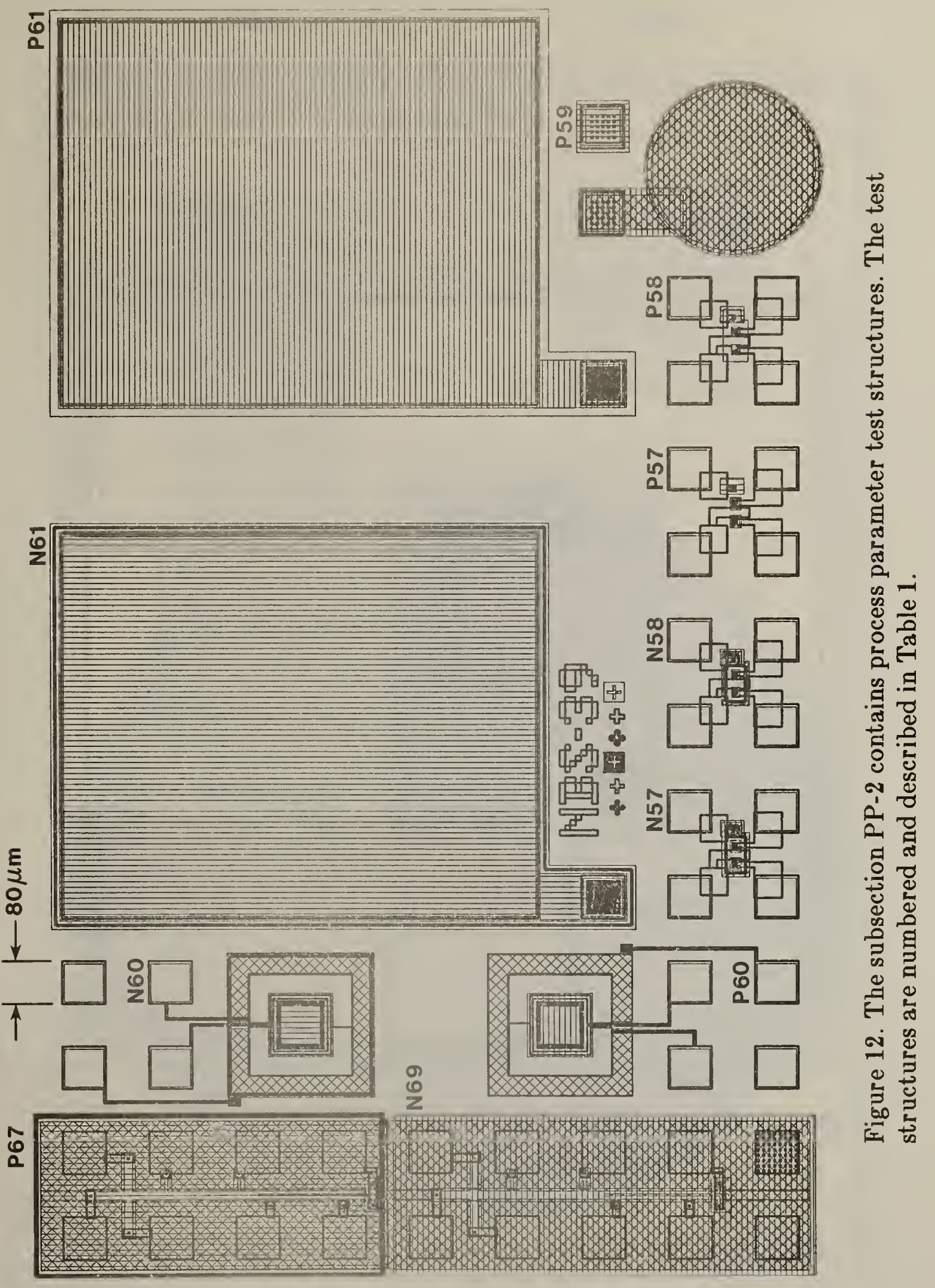




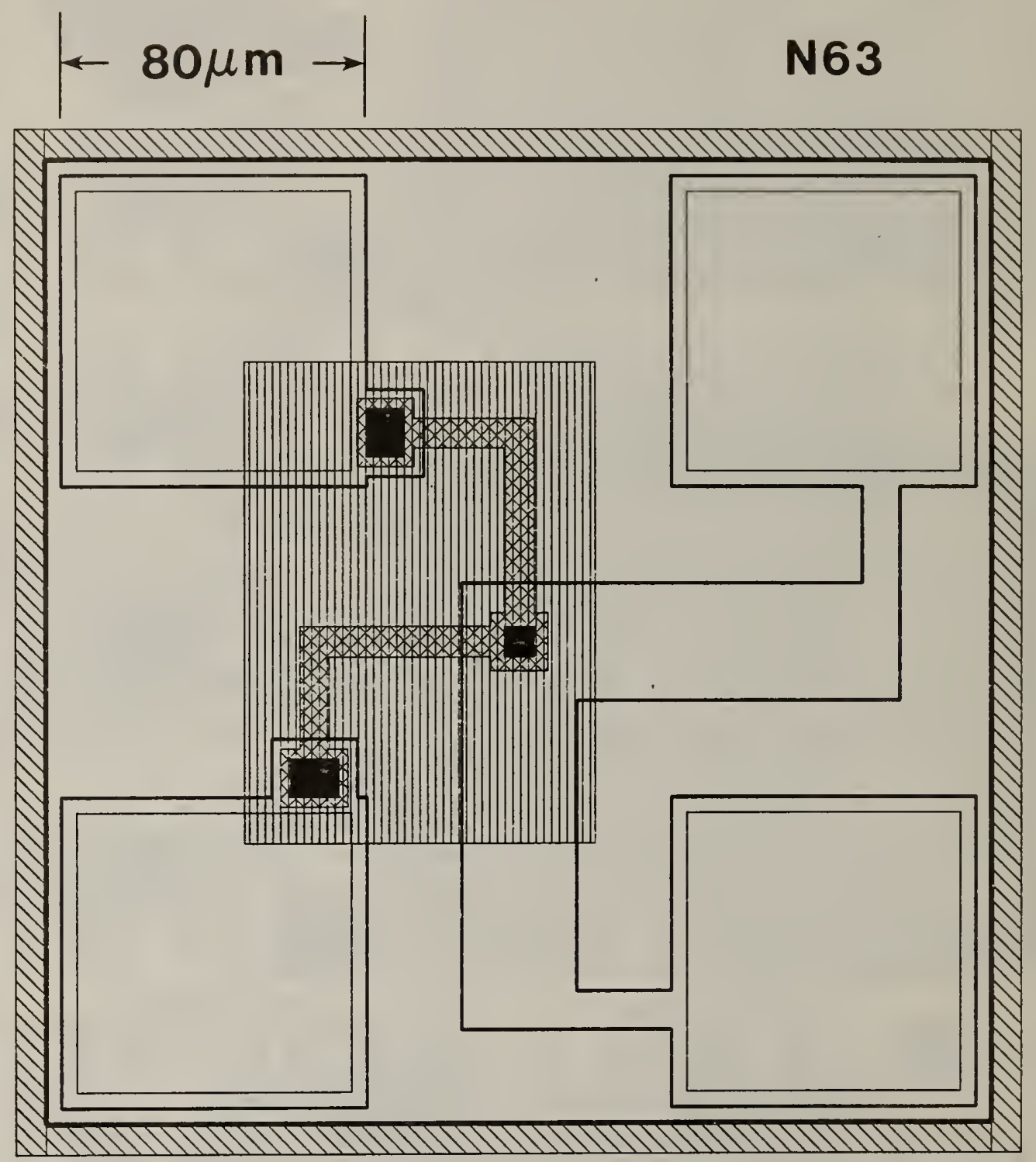

Figure 13. A contact resistor test structure, N63, from subsection PP-1. 


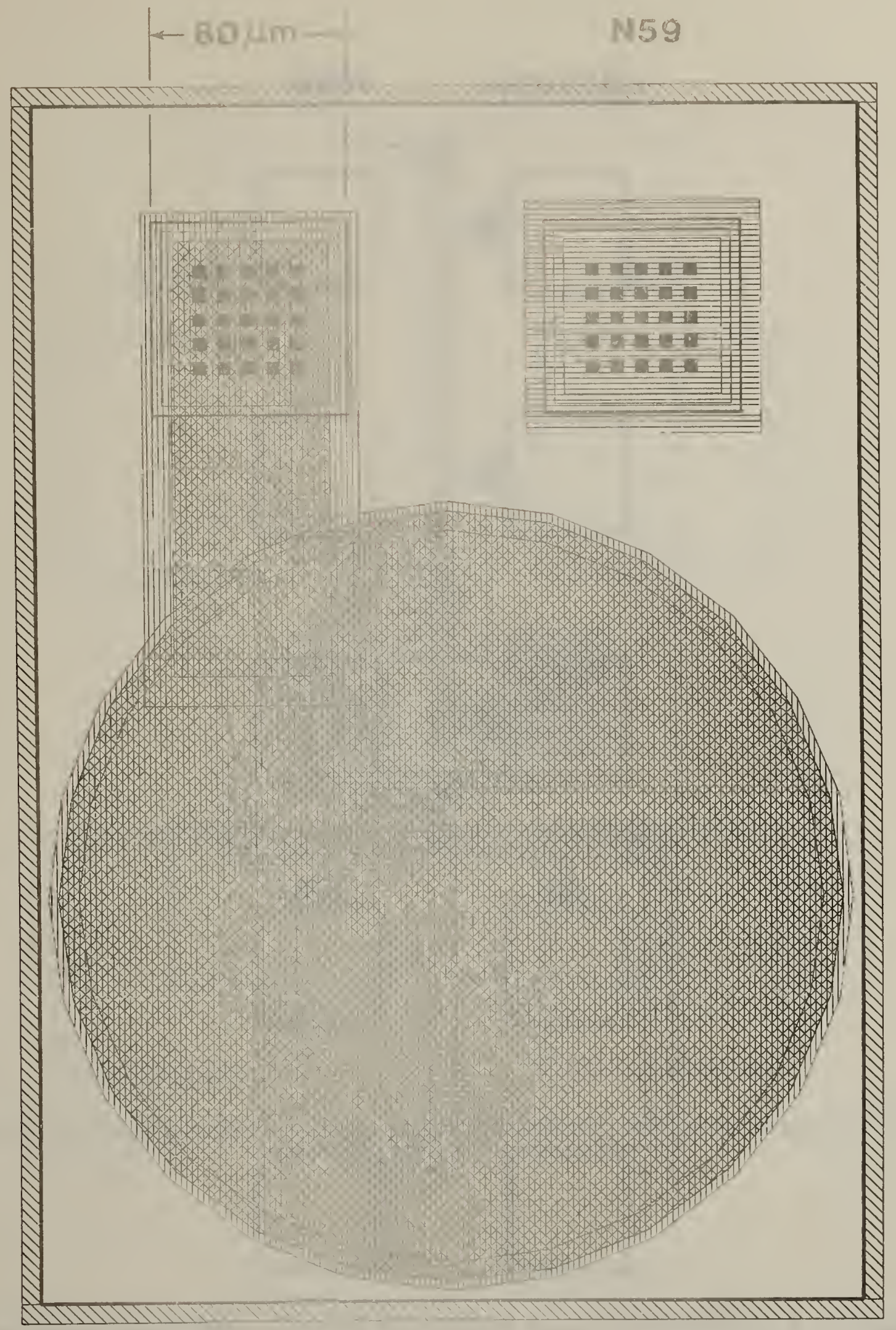

Figure 14. An MOJ begacituated stencture, N59, irom subsection PP-1. 


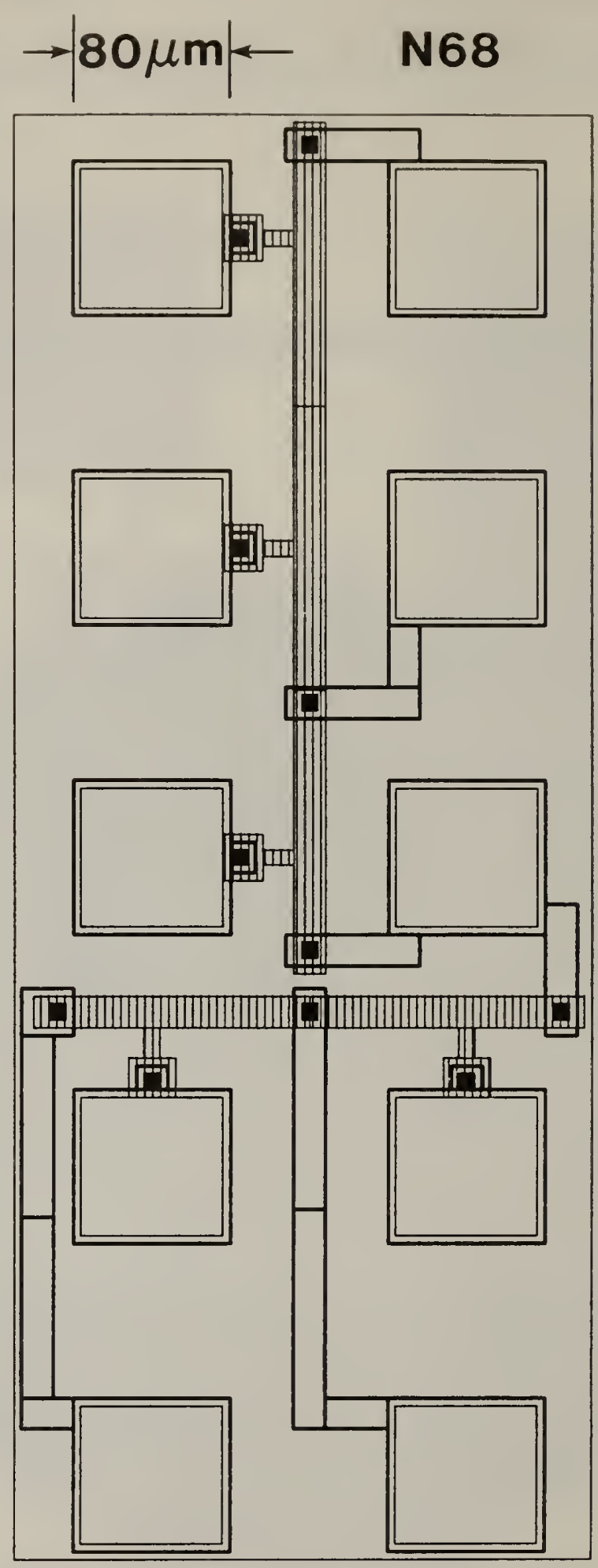

Figure 15. An electrical alignment resistor test structure, N68, from subsection PP1. 


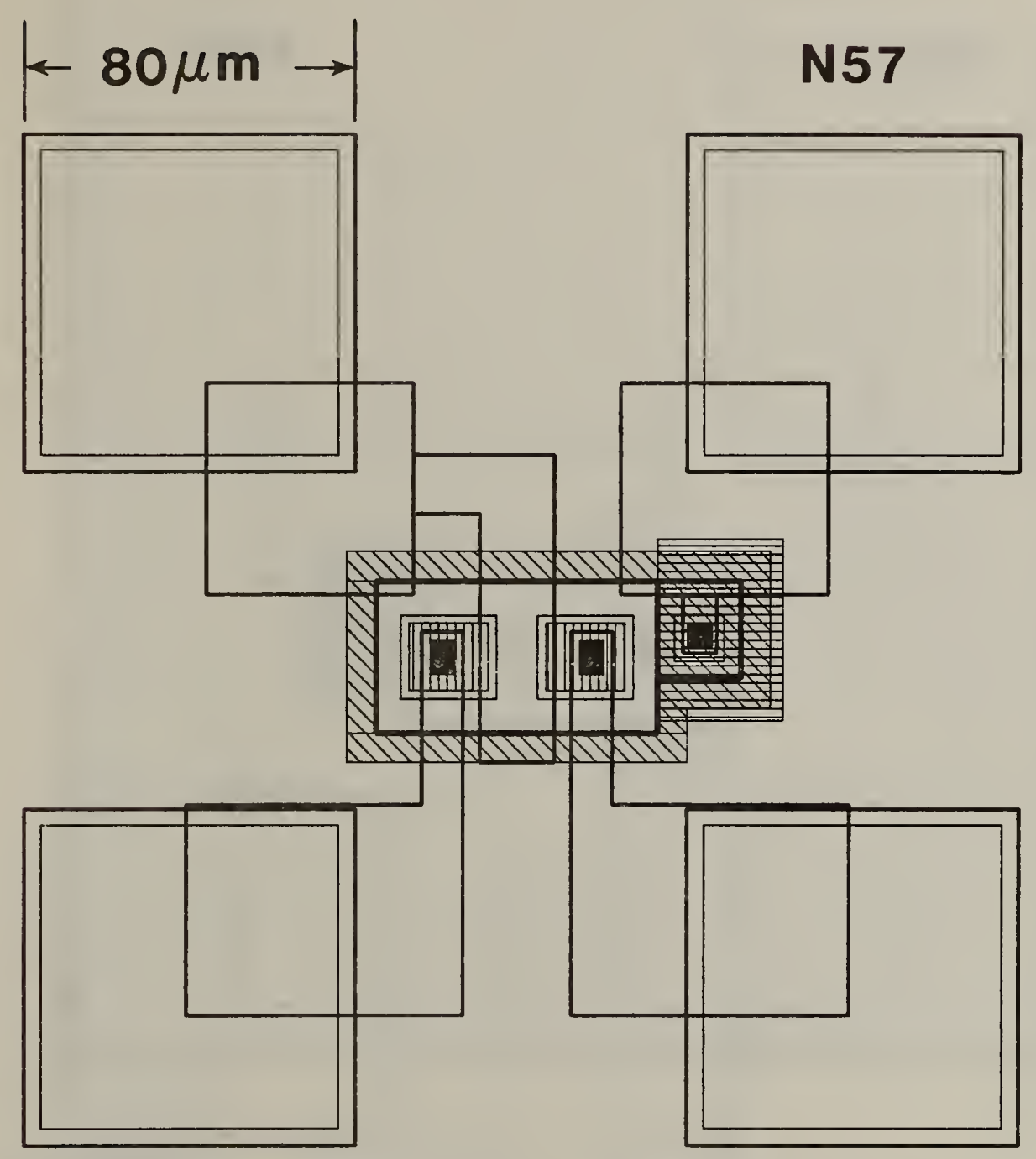

Figure 16. A metal gate field oxide $n$-channel MOSFET, N57, from subsection PP2. 


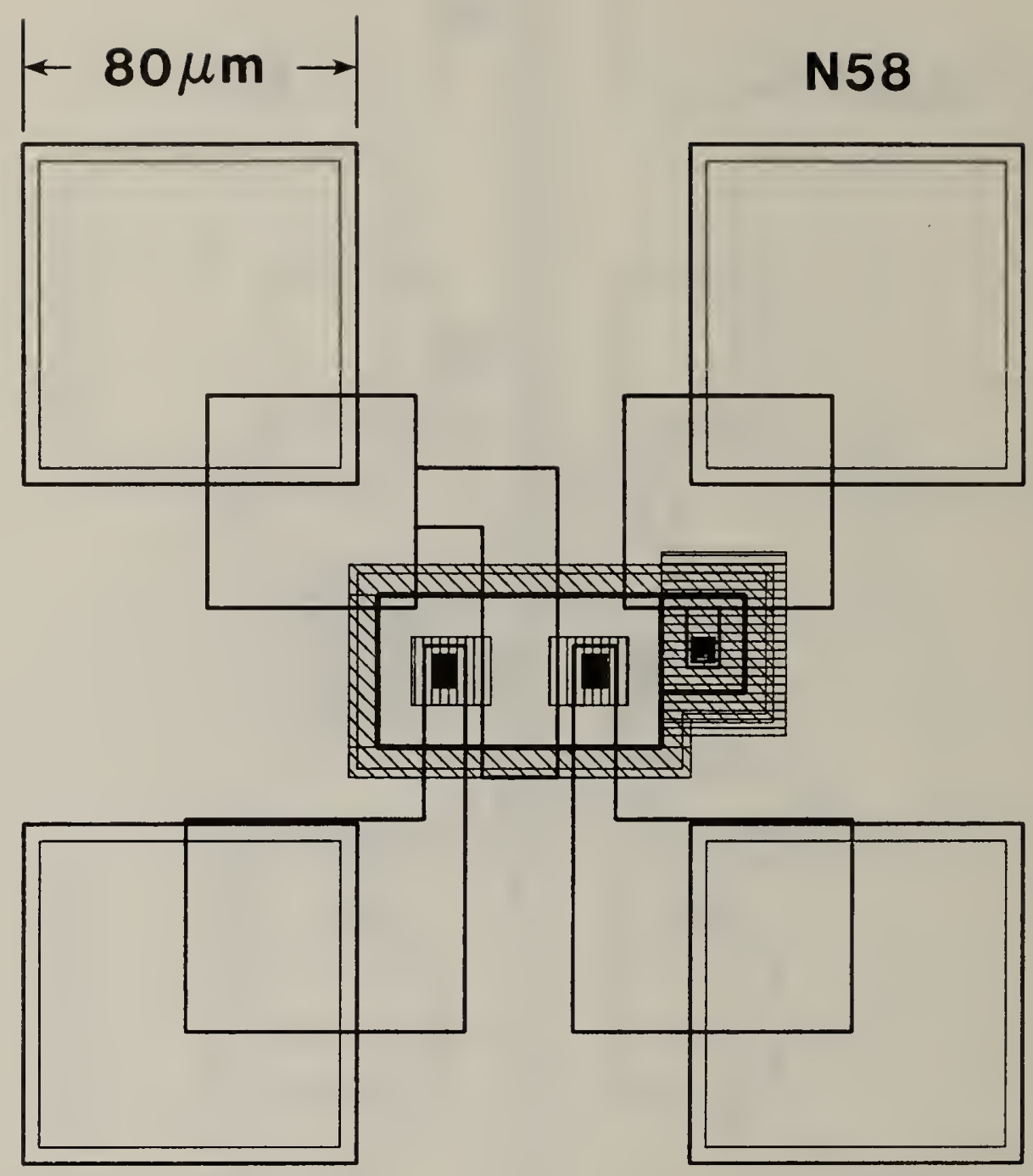

Figure 17. A metal gate intermediate oxide $n$-channel MOSFET, N58, from subsection PP-2. 
N61

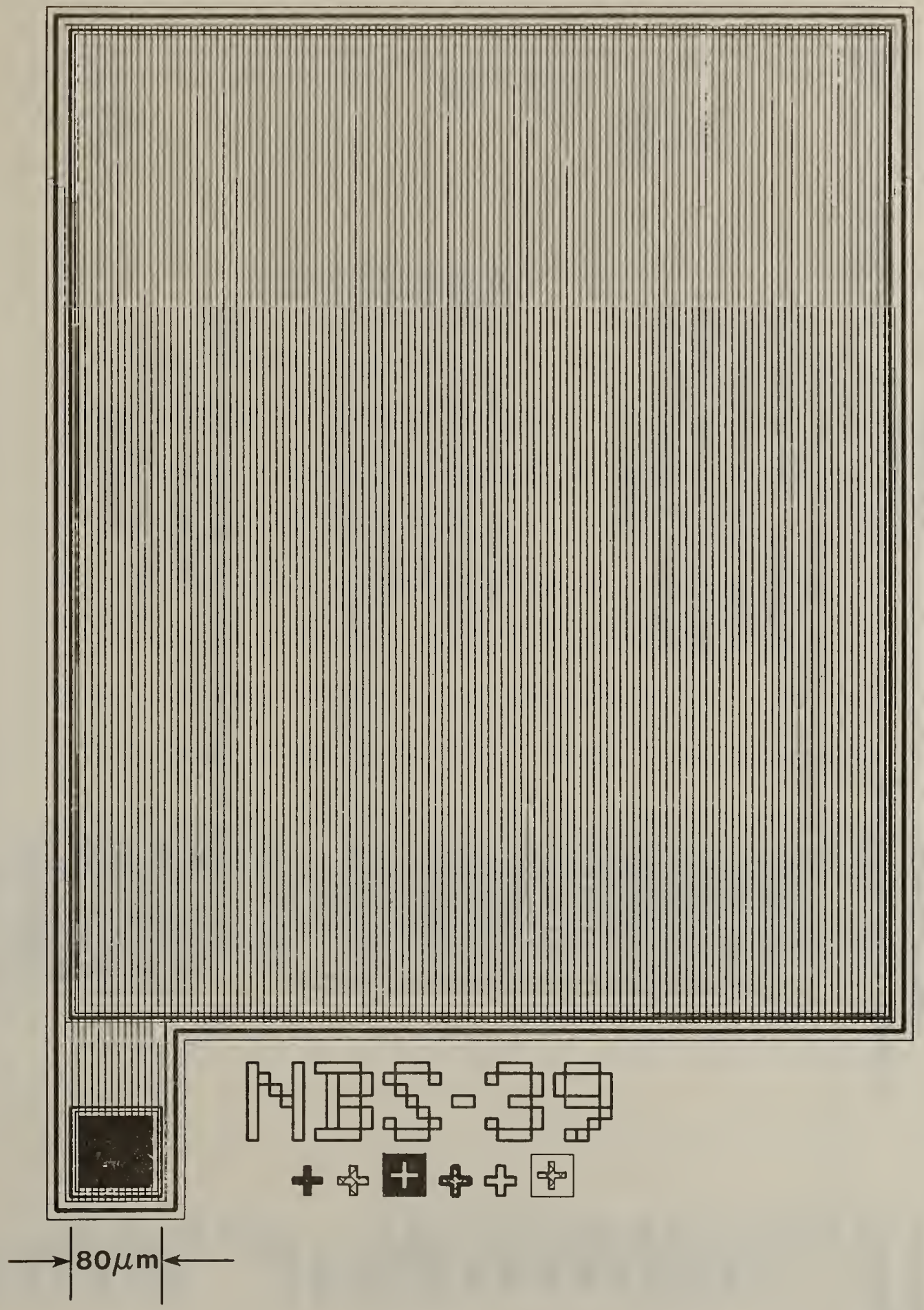

Figure 18. An $n^{+}$secondary ion mass spectroscopy(SIMS) profiling target, N61, from subsection PP-2. 


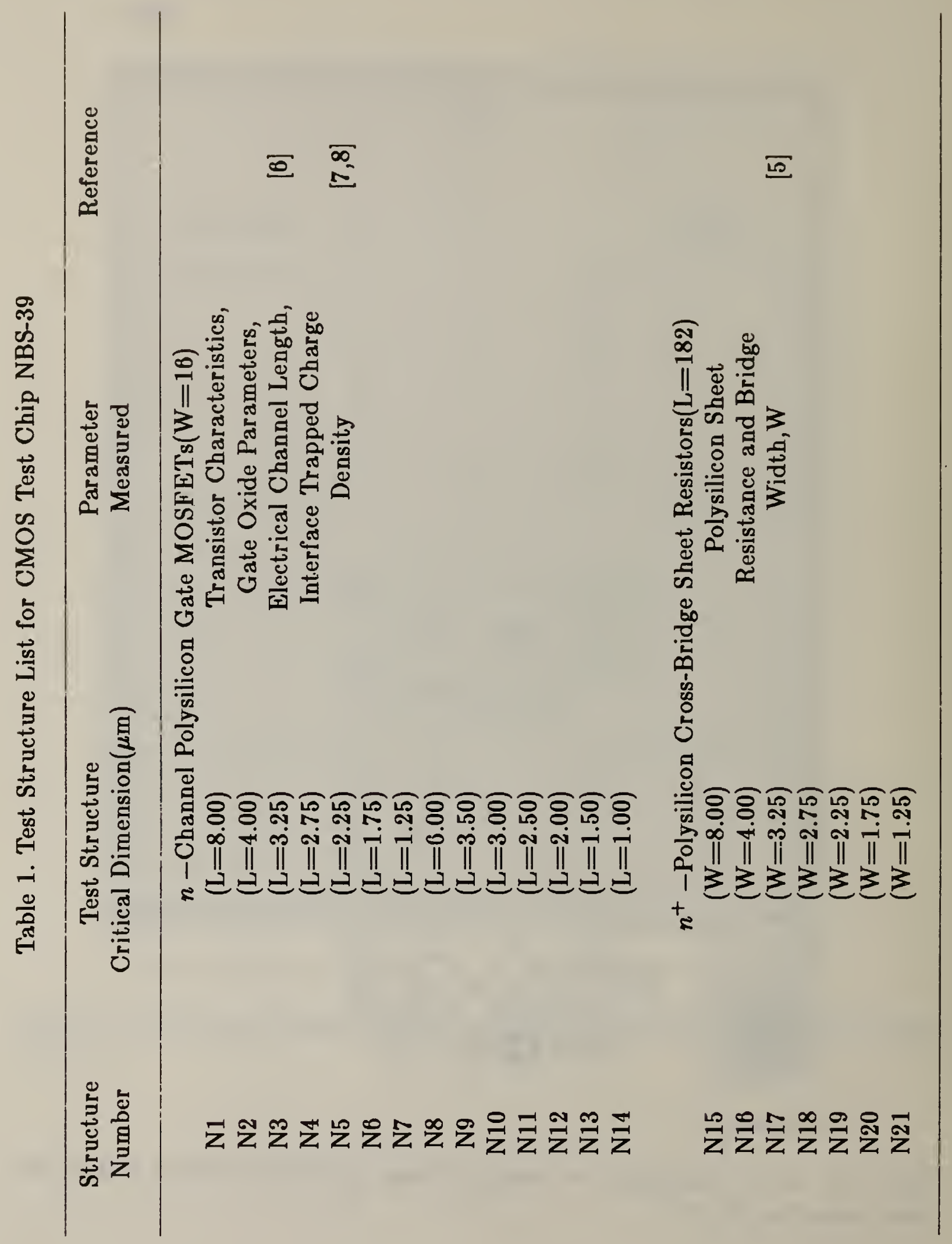



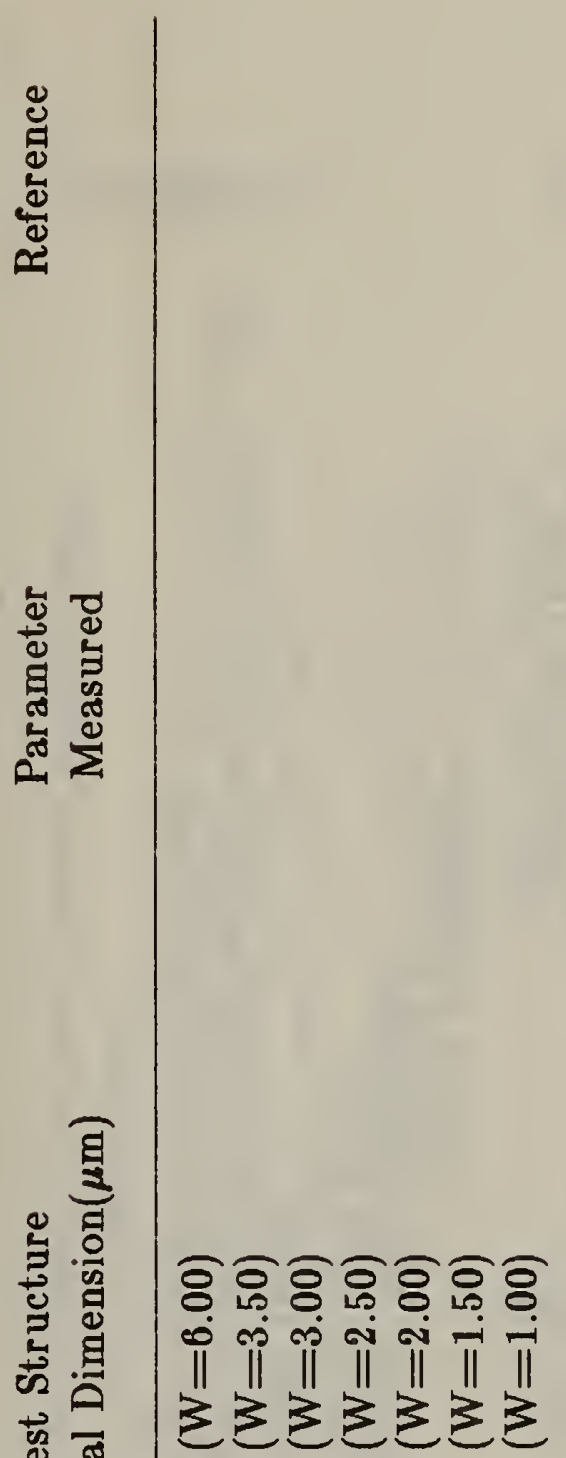

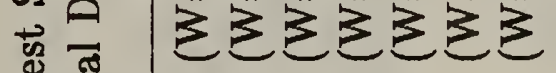

总岁

$$
\infty \quad \infty
$$

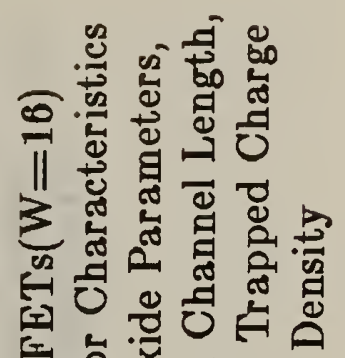

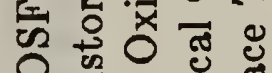

$\sum$.

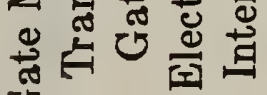

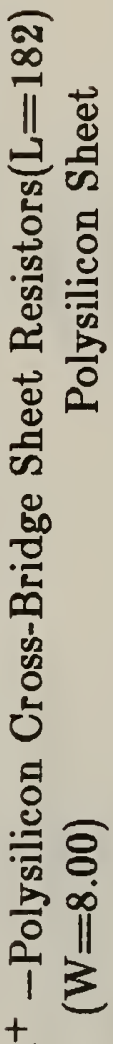

$+$

\section{สำ

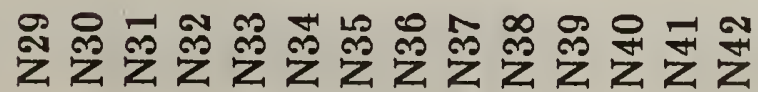 \\ 呟}


[2]

Eᄑ표

苞

용

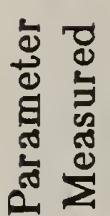

$\stackrel{0}{\infty}$

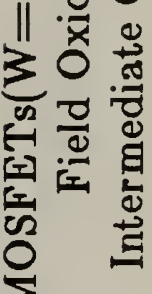

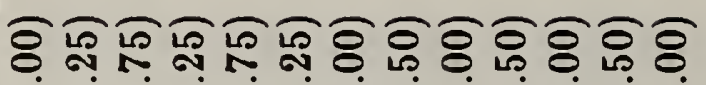

$\stackrel{0}{\pi}$

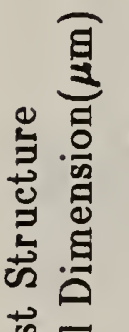

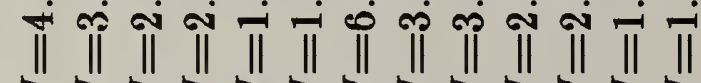

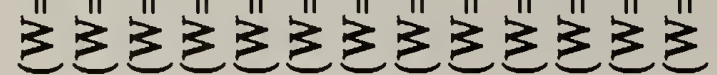

$\sum^{\infty}$

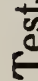

论

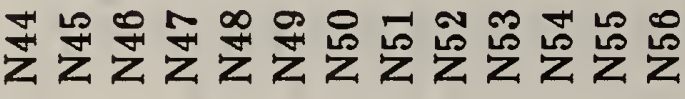

㤎

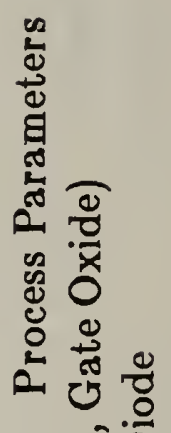

สิ

$\stackrel{-1}{+1}$

$\stackrel{0}{11}$

ำ

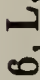

II

$\sum_{\substack{\infty \\ 0}}^{\infty}$

.

开

:

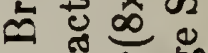

坣

获

잉. 可 व । ज्ञ

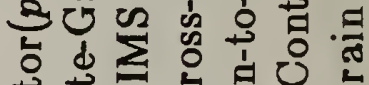

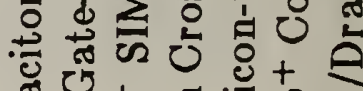

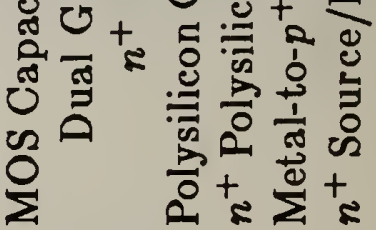
究

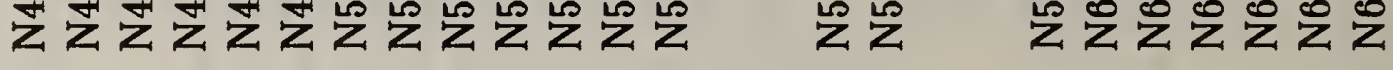




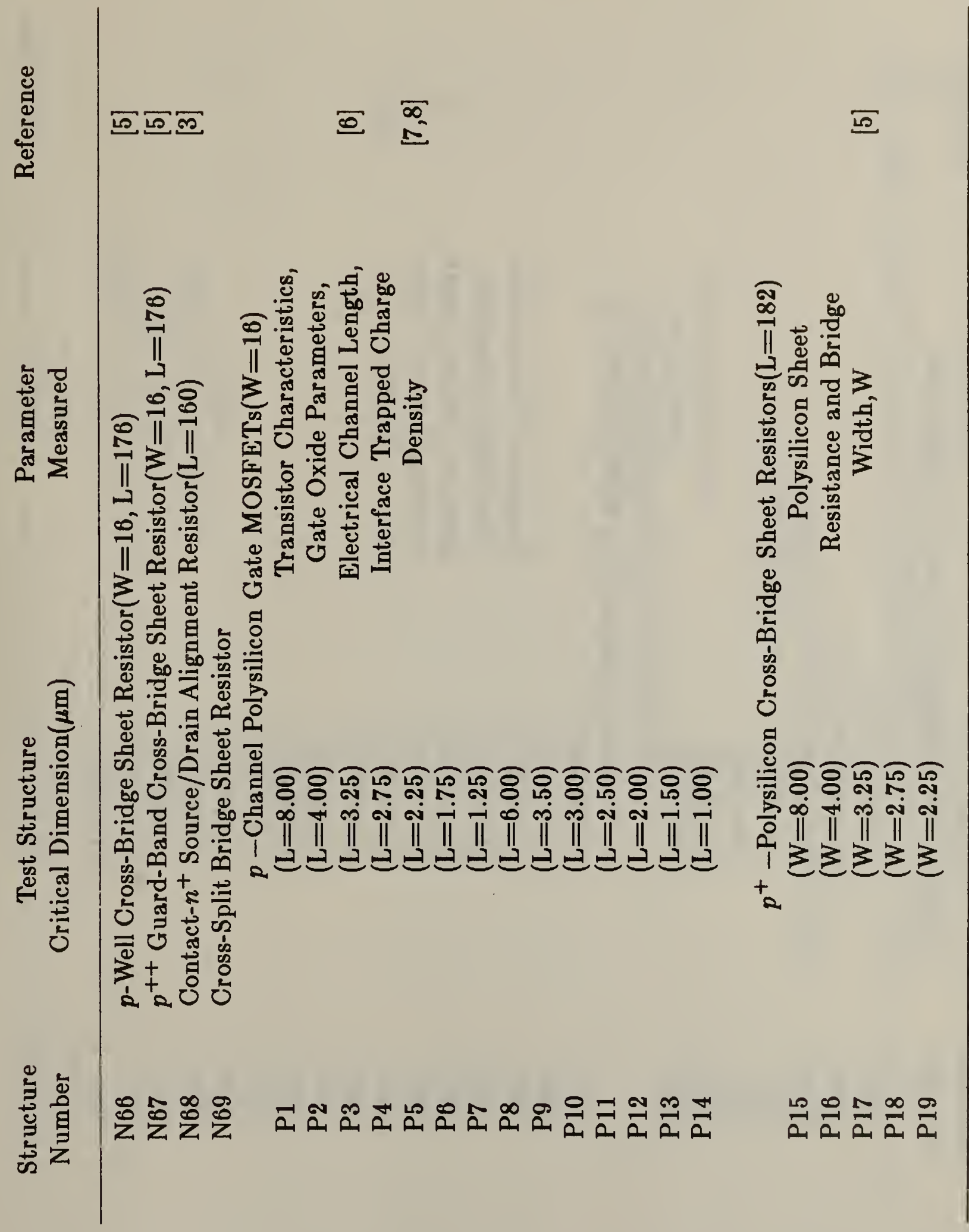




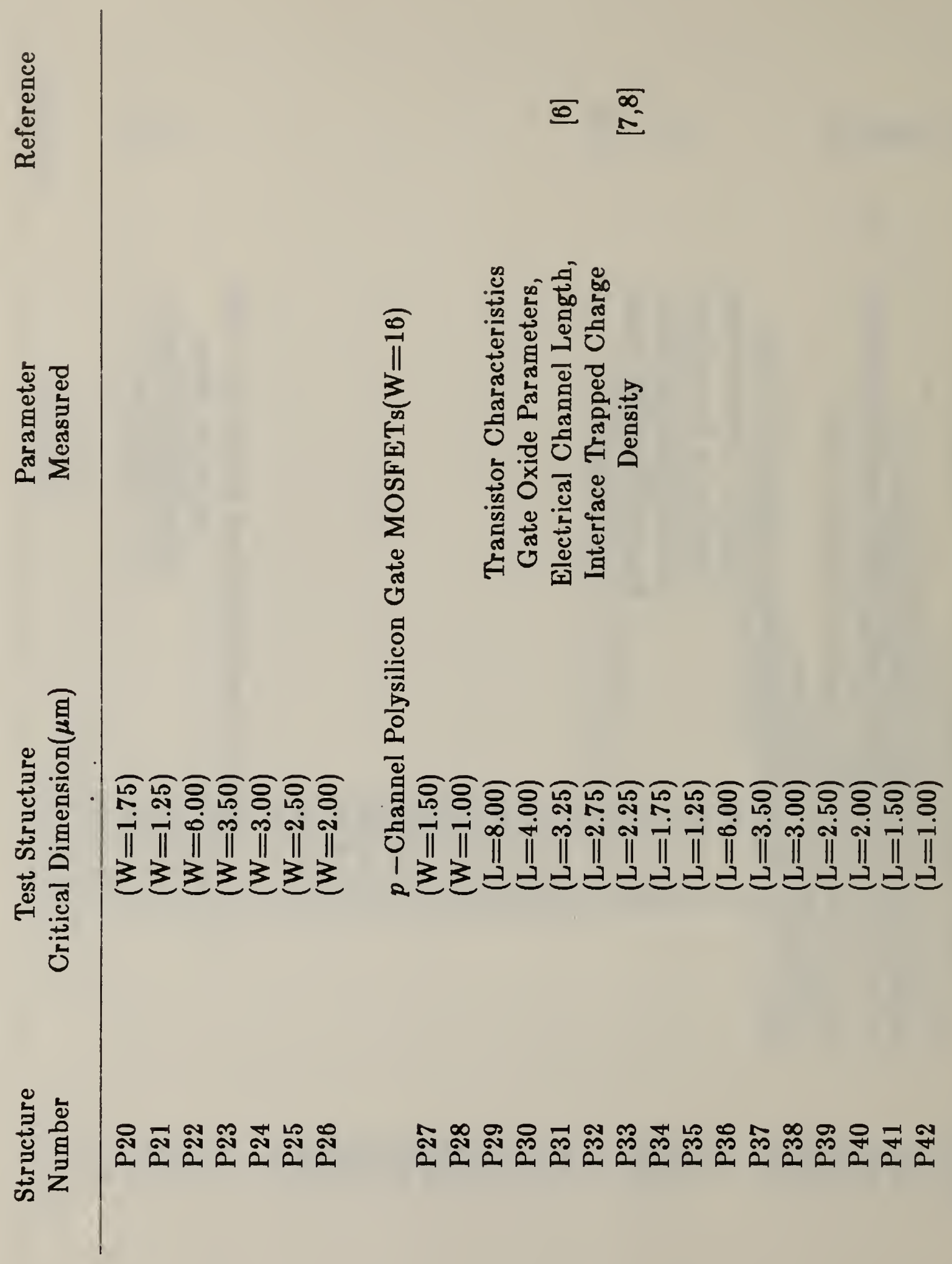




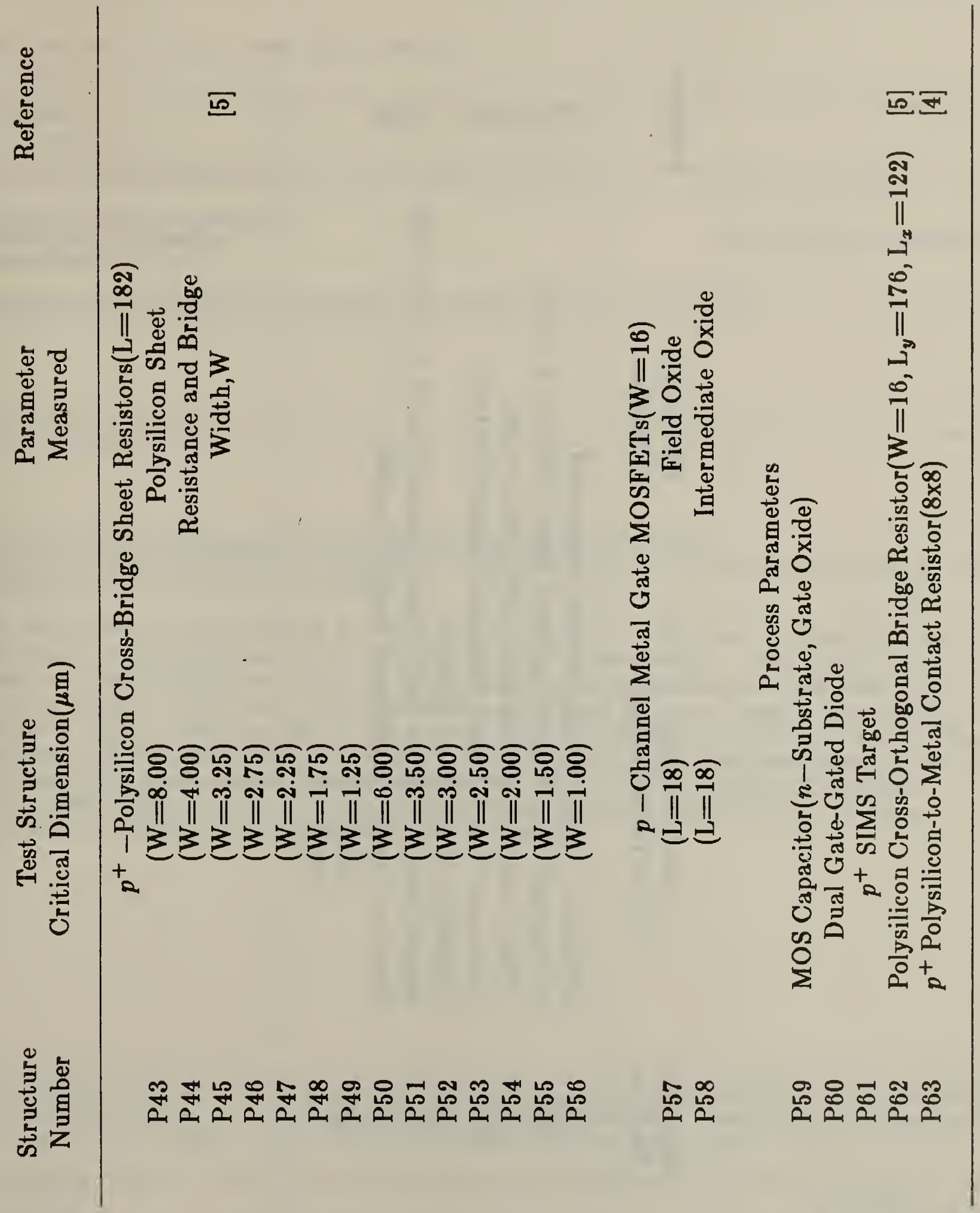




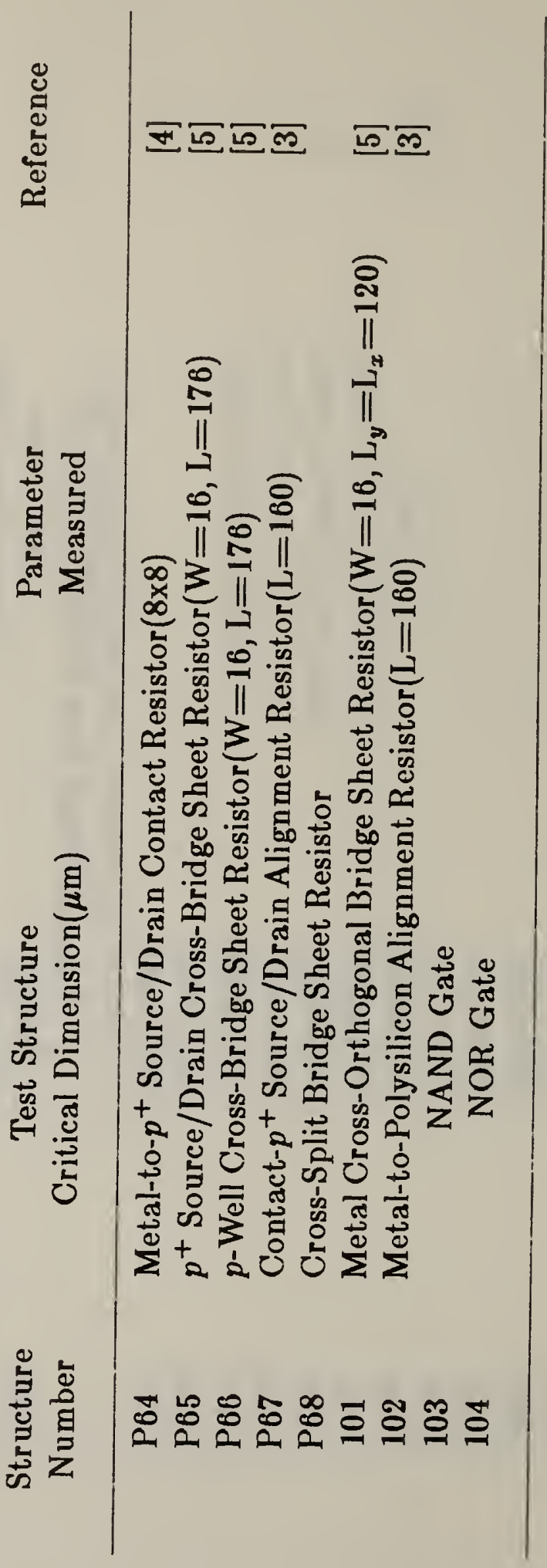


NBS-114A (REV. 2-8C)

U.S. DEPT. OF COMM.

1. PUBLICATION OR REPORT NO.

NBSIR 83-2683
2. Performing Organ. Report Nod

3. Publication Date

April 1983

SHEET (See in structions)

4. TITLE AND SUBTITLE

Description of a CMOS Test Chip, NBS-39

5. AUTHOR(S)

T. J. Russell

6. PERFORMING ORGANIZATION (If joint or other than NBS, see instructions) -

7. Contract/Grant No.

NATIONAL BUREAU OF STANDARDS

DEPARTMENT OF COMMERCE

WASHINGTON, D.C. 20234

9. SPONSORING ORGANIZATION NAME AND COMPLETE ADDRESS (Street, City, Stote, ZIP)

8. Type of Report \& Period Covered

10. SUPPLEMENTARY NOTES

Document describes a computer program; SF-185, FIPS Software Summary, is attached.

11. ABSTRACT (A 200-word or less foctual summory of most significant information. If document includes o significant bibliogrophy or literoture survey. mention it here)

Test chip NBS-39 was designed to analyze the scaling properties of short-channel metal-oxide-semiconductor field effect transistors (MOSFETs). This report is a guide for identifying and locating each test structure included on the test chip. There is a table with each test structure identified by name, number, parameter measured, and a reference of how to perform the measurement when appropriate. The test chip can be fabricated by a junction-isolated (JI) silicon complementary metaloxide semiconductor (CMOS) p-well process and by a local oxidation of silicon (LOCOS) CMOS p-well process. The modifications required to go from a JI-CMOS fabrication process to a LOCOS-CMOS are discussed.

12. KEY WORDS (Six to twelve entries: alphabetical order; capitalize only proper names; and separate key words by semicolons) CMOS; MOSFETs; p-well junction-isolated (JI) CMOS process; p-well local oxidation of silicon (LOCOS) CMOS process; scaling; short-channel; test chip; test structure.

13. AVAILABILITY

X] Unlimited

For Official Distribution. Do Not Release to NTIS

$\square$ Order From Superintendent of Documents, U.S. Government Printing Office, Washington, D.C. 20402.

X. Order From National Technical Information Service (NTIS), Springfield, VA. 22161
14. NO. OF PRINTED PAGES 36

15. Price

$\$ 8.50$ 


